\title{
Magnetic Resonance Imaging of the Heart
}

\section{Image quality, measurement accuracy and patient experience}

\author{
Britt-Marie Ahlander
}

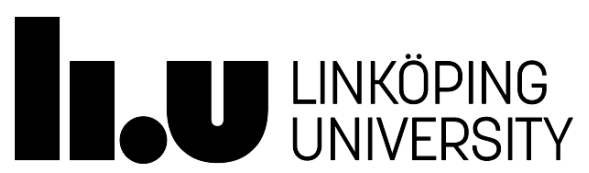

Department of Medical and Health Sciences

Linköping University, Sweden

Linköping 2016 
(C)Britt-Marie Ahlander, 2016

Cover, Per Lagman, with permission Siemens Healthineers.

Published article has been reprinted with the permission of the copyright holder.

Printed in Sweden by LiU-Tryck, Linköping, Sweden, 2016

ISBN 978-91-7685-742-7

ISSN $0345-0082$ 
"Att våga är att förlora fotfästet en liten stund".

Sören Kirkegaard (1813-1855) 



\section{CONTENTS}

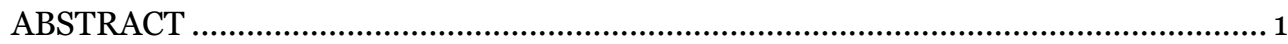

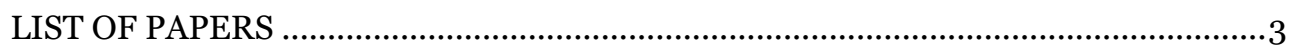

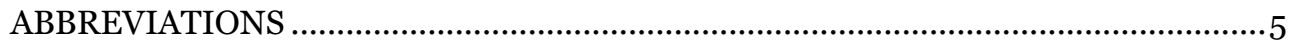

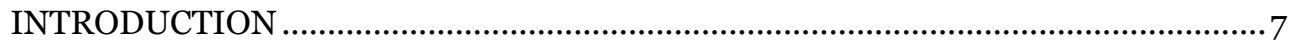

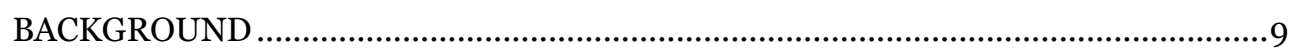

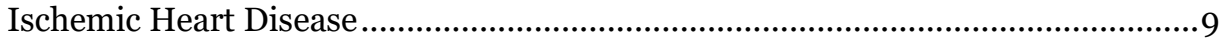

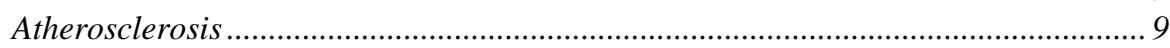

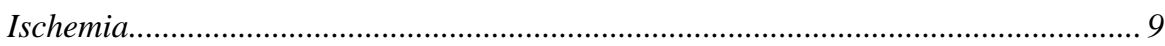

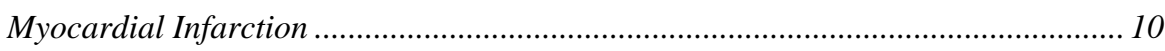

Magnetic Resonance Imaging ........................................................................11

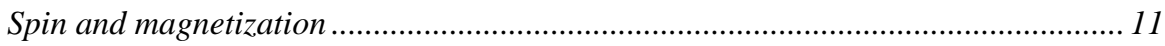

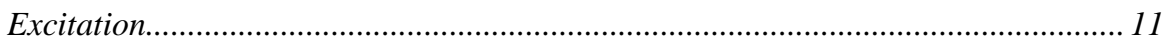

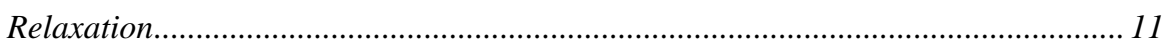

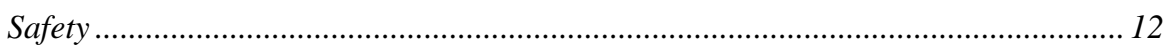

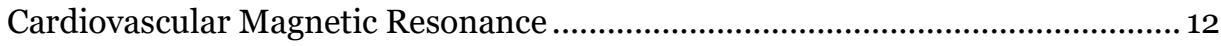

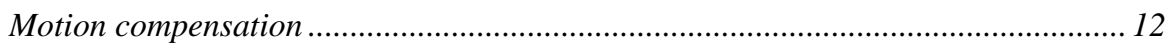

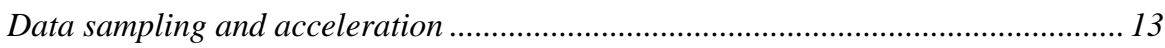

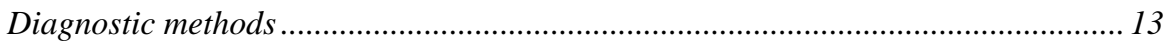

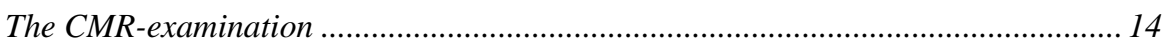

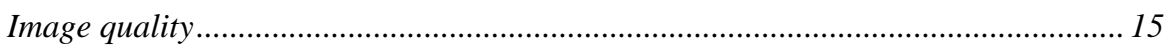

Single photon emission computed tomography ............................................. 16

Myocardial Perfusion SPECT .............................................................................. 16

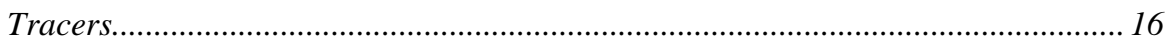

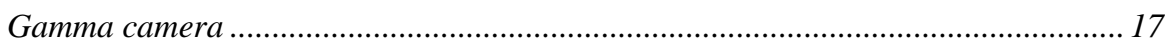

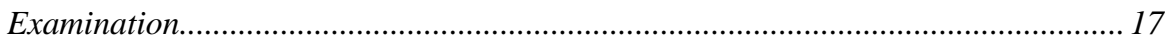

Well-being in the context of MRI.............................................................. 17

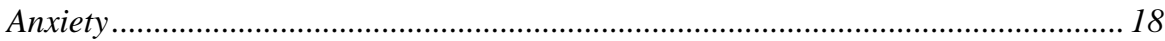

How to psychologically prepare the patient for the MRI study ............................... 19

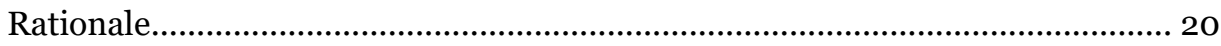

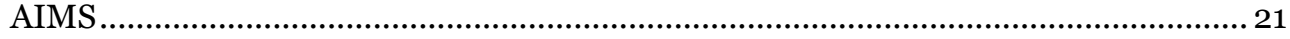

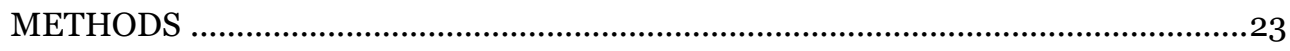

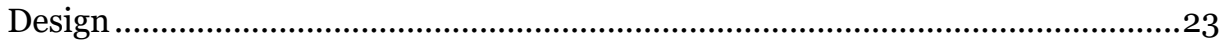

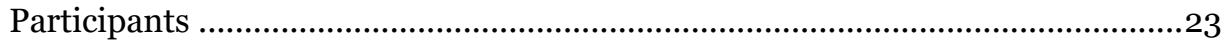




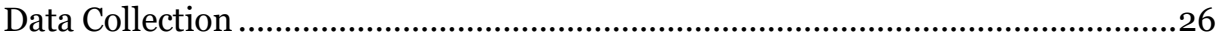

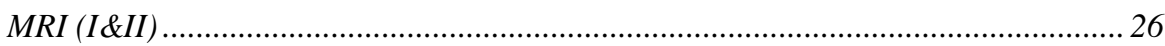

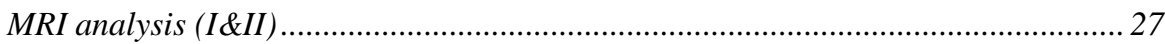

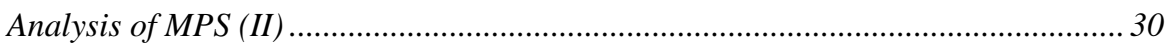

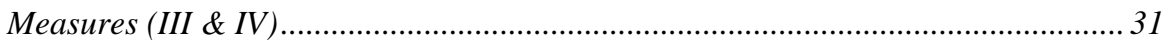

Development of Magnetic Resonance Imaging-Anxiety Questionnaire (MRI-

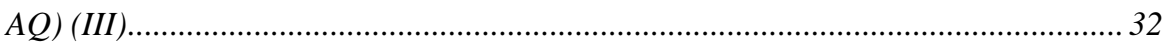

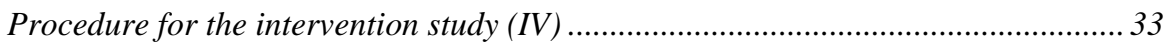

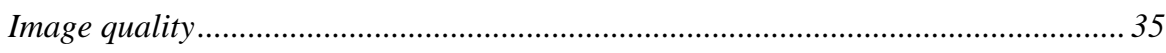

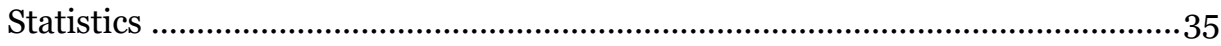

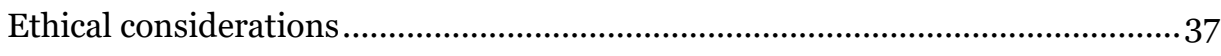

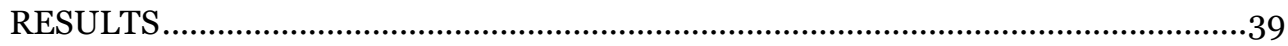

In patients with ongoing atrial fibrillation, a SS-SSFP sequence showed

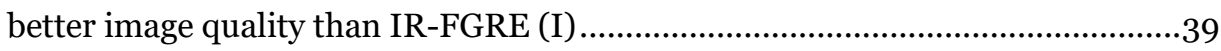

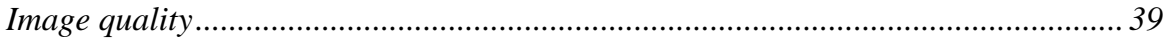

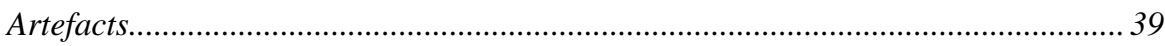

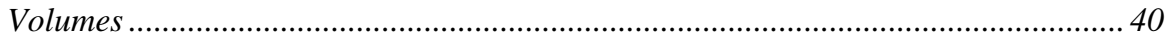

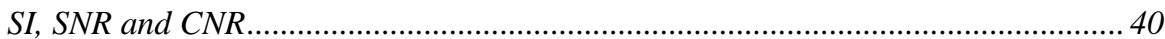

For visual and quantitative evaluation of CMR stress first-pass perfusion, a GRE-EPI sequence demonstrated higher agreement with MPS than a SSFP

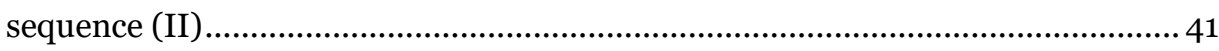

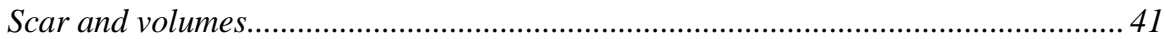

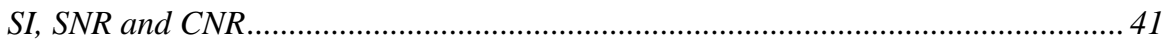

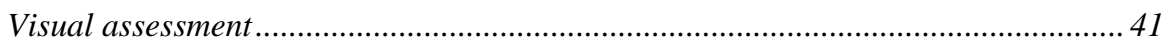

Quantitative segmental CMR and MPS.............................................................. 43

Development of the Magnetic Resonance Imaging Anxiety Questionnaire MRI-AQ (Paper III) ................................................................................44

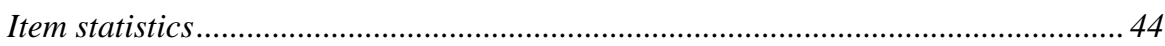

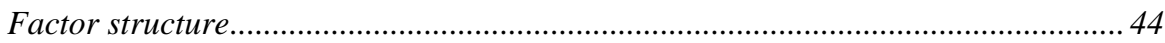

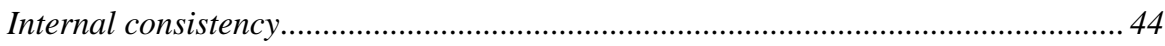

Criterion related and known-group validity ........................................................... 44

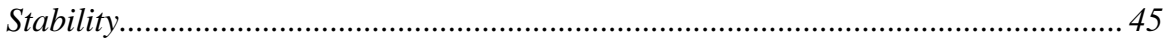

Video information prior to CMR examination resulted in more relaxed patients, but motion artefacts were not reduced. Patients who underwent CMR had higher levels of anxiety than those who underwent MPS (Paper

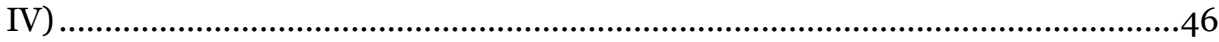

Comparisons immediately after the examinations .................................................... 46

Comparison of image quality ................................................................................ 48

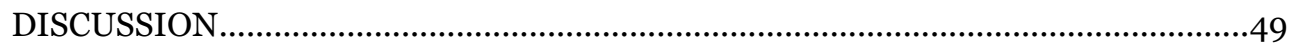

Aspects on participants and methods .........................................................49 


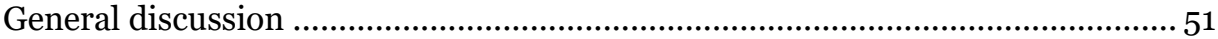

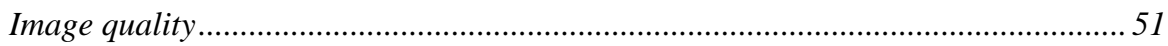

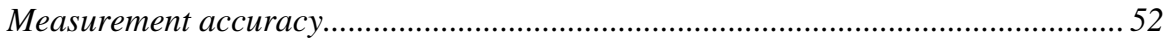

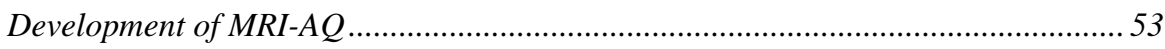

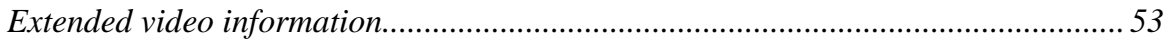

Clinical implications and future studies ......................................................... 55

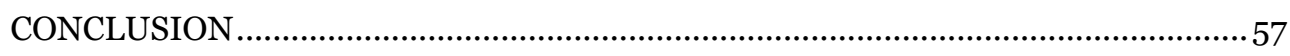

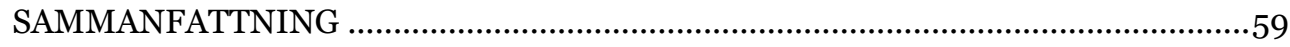

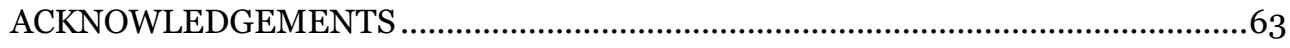

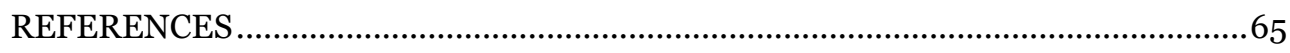

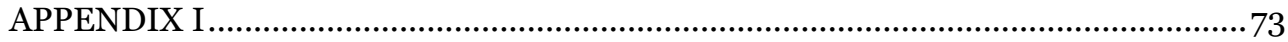

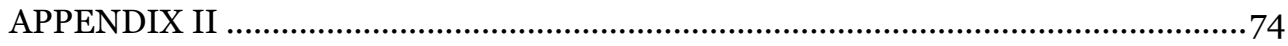




\section{ABSTRACT}

Background: Non-invasive diagnostic imaging of atherosclerotic coronary artery disease (CAD) is frequently carried out with cardiovascular magnetic resonance imaging (CMR) or myocardial perfusion single photon emission computed tomography (MPS). CMR is the gold standard for the evaluation of scar after myocardial infarction and MPS the clinical gold standard for ischemia. Magnetic Resonance Imaging (MRI) is at times difficult for patients and may induce anxiety while patient experience of MPS is largely unknown.

Aims: To evaluate image quality in CMR with respect to the sequences employed, the influence of atrial fibrillation, myocardial perfusion and the impact of patient information. Further, to study patient experience in relation to MRI with the goal of improving the care of these patients.

Method: Four study designs have been used. In paper I, experimental crossover, paper (II) experimental controlled clinical trial, paper (III) psychometric cross-sectional study and paper (IV) prospective intervention study. A total of 475 patients $\geq 18$ years with primarily cardiac problems (I-IV) except for those referred for MRI of the spine (III) were included in the four studies.

Result: In patients $(n=20)$ with atrial fibrillation, a single shot steady state free precession (SS-SSFP) sequence showed significantly better image quality than the standard segmented inversion recovery fast gradient echo (IR-FGRE) sequence (I). In first-pass perfusion imaging the gradient echo-echo planar imaging sequence (GRE-EPI) $(\mathrm{n}=3 \mathrm{O})$ had lower signal-to-noise and contrastto-noise ratios than the steady state free precession sequence (SSFP) $(n=30)$ but displayed a higher correlation with the MPS results, evaluated both qualitatively and quantitatively (II). The MRI-Anxiety Questionnaire (MRI-AQ) was validated on patients, referred for MRI of either the spine $(n=193)$ or the heart $(n=54)$. The final instrument had 15 items divided in two factors regarding Anxiety and Relaxation. The instrument was found to have satisfactory psychometric properties (III). Patients who prior CMR viewed an information video scored significantly (lower) better in the factor Relaxation, than those who received standard information. Patients who underwent MPS scored lower on both factors, Anxiety and Relaxation. The extra video information had no effect on CMR image quality (IV).

Conclusion: Single shot imaging in atrial fibrillation produced images with less artefact than a segmented sequence. In first-pass perfusion imaging, the sequence GRE-EPI was superior to SSFP. A questionnaire depicting anxiety during MRI showed that video information prior to imaging helped patients relax but did not result in an improvement in image quality. 


\section{LIST OF PAPERS}

Rosendahl L, Ahlander BM, Bjorklund PG, Blomstrand P, Brudin L, Engvall JE: Image quality and myocardial scar size determined with magnetic resonance imaging in patients with permanent atrial fibrillation: a comparison of two imaging protocols. Clin Physiol Funct Imaging. 2010 Mar;30(2):122-9. doi: 10.1111/j.1475-097X.2009.00914.x. Epub 2009 Dec 23.

Ahlander BM, Maret E, Brudin L, Starck SA, Engvall J: An echo-planar imaging sequence is superior to a steady-state free precession sequence for visual as well as quantitative assessment of cardiac magnetic resonance stress perfusion. Clin Physiol Funct Imaging. Jul 4. doi: 10.1111/cpf.12267. [Epub ahead of print]

Ahlander BM, Arestedt K, Engvall J, Maret E, Ericsson E: Development and validation of a questionnaire evaluating patient anxiety during Magnetic Resonance Imaging: the Magnetic Resonance Imaging-Anxiety Questionnaire (MRI-AQ). J Adv Nurs. 2016 Jun;72(6):1368-80. doi: 10.1111/jan.12917. Epub $2016 \mathrm{Feb} 18$.

Ahlander BM, Engvall J, Maret E, Ericsson E: Video information prior to cardiovascular magnetic resonance improves patient experience which still remains more challenging than in myocardial perfusion scintigraphy. Submitted. 


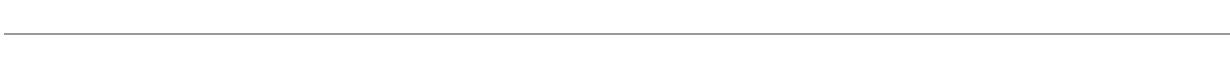




\section{ABBREVIATIONS}

$\begin{array}{ll}\text { ANOVA } & \text { Analysis Of Variance } \\ \text { BSA } & \text { Body Surface Area } \\ \text { CABG } & \text { Coronary Artery Bypass Graft } \\ \text { CAD } & \text { Coronary Artery Disease } \\ \text { CAQ } & \text { Cardiac Anxiety Questionnaire } \\ \text { CMR } & \text { Cardiovascular Magnetic Resonance } \\ \text { CNR } & \text { Contrast-to-Noise Ratio } \\ \text { CVI } & \text { Content Validity Index } \\ \text { ECG } & \text { ElectroCardioGram } \\ \text { Echo } & \text { Echocardiography } \\ \text { FLASH } & \text { Fast Low Angle Shot } \\ \text { Gd } & \text { Gadolinium } \\ \text { GFR } & \text { Glomerular Filtration Rate } \\ \text { GRAPPA } & \text { Generalized Autocalibrating Partially Parallel Acquisitions } \\ \text { GRE-EPI } & \text { Gradient Echo-Echo Planar Imaging } \\ \text { HAD } & \text { Hospital Anxiety and Depression scale } \\ \text { ICA } & \text { Invasive Coronary Angiography } \\ \text { IR } & \text { Inversion Recovery } \\ \text { IR-FGRE } & \text { Inversion Recovery -Fast Gradient echo sequence } \\ \text { IQR } & \text { Interquartile range } \\ \text { LDL } & \text { Low-Density-Lipoprotein } \\ \text { LGE } & \text { Late Gadolinium Enhancement } \\ \text { LV } & \text { Left Ventricle } \\ \text { LVEDV } & \text { Left Ventricular end Diastolic Volume } \\ \text { LVEF } & \text { Left Ventricle Ejection Fraction } \\ \text { m } & \text { mean } \\ \text { med } & \text { median } \\ \text { MI } & \text { Myocardial Infarction } \\ \text { MHz } & \text { MegaHertz } \\ \text { MPS } & \text { Myocardial Perfusion SPECT } \\ \text { MRI } & \text { Magnetic Resonance Imaging } \\ \text { MRI-AQ } & \text { Magnetic Resonance Imaging- Anxiety Questionnaire } \\ \text { MRI-FSS } & \text { Magnetic Resonance Imaging -Fear Survey Schedule } \\ & \\ \text { Le }\end{array}$


PCI Percutaneous Coronary Intervention

PET Positron Emission Tomography

PMT Photomultiplier Tubes

ROI Region of Interest

SD Standard Deviation

SENSE Sensitivity Encoding

SI Signal Intensity

SNR Signal-to-Noise Ratio

SPECT Single Photon Emission Computed Tomography

SSFP Steady State Free Precession

SS-SSFP Single Shot Steady State Free Precession

STAI-S Spielberg State Anxiety Index - State

T Tesla

WMSI Wall Motion Score Index 


\section{INTRODUCTION}

Magnetic Resonance Imaging (MRI) is a complicated medical imaging technique [1]. It is useful in a wide range of conditions, such as in cardiovascular investigations, where the ability to investigate tissue characterization can be fully exploited. Technical developments have produced advanced scanners and a large number of sequences to use. The manufacturers propose ways they perceive to be the most successful in building sequences. However, we need to evaluate the performance of each sequence in the clinical setting. New sequences have to be critically evaluated with the patient's best interest in mind.

Being a patient is always associated with distress and anxiety. High technology environments, such as an MRI suite, could be experienced as threatening and alienate the patient from the staff [2]. The patients are left alone in the scanner with the operating staff in an adjacent room. Patients may feel abandoned when the staff is fully focused on running the imaging equipment. This may result in sub-standard care [3].

Cardiovascular disease is the most common cause of death in Europe [4]. Having a cardiac condition is frequently perceived to be life-threatening and may create a state of anxiety in patients [5]. The combination of undergoing a cardiovascular magnetic resonance (CMR) imaging procedure and having a potential lifethreatening cardiac disease, may add to the state of anxiety.

Information frequently reduces anxiety [6], but the scope of information required differs among patients. Some need details while others prefer a superficial orientation. Patient information should be given in plain language that is easy to understand for everyone [7]. 


\section{BACKGROUND}

\section{Ischemic Heart Disease}

\section{Atherosclerosis}

Atherosclerotic coronary artery disease (CAD) includes a broad spectrum of conditions from asymptomatic atherosclerosis to myocardial infarction (MI) and sudden death. It is characterized by fibrotic thickening of the intima associated with lipid infiltrated plaque seen in large and medium sized arteries [8]. Inflammatory and immune cells are an important part of the plaque. The atheromatous plaque is preceded by fatty streaks mostly consisting of macrophages and some T-cells [9].

Atherosclerosis begins in childhood and slowly progresses over time [10]. Acceleration of disease, causing premature manifestations, can be induced by hereditary as well as environmental factors [11]. The general heritability of CAD is difficult to prove because of the complex interaction between heredity and environment. However, an early onset of $\mathrm{CAD}$ in first degree relatives is significantly associated with and predicts early onset of CAD [12]. The penetrance of hereditary factors in $\mathrm{CAD}$ is in the range $40-60 \%[13,14]$. The risk increases with higher numbers of first degree relatives with $\mathrm{CAD}$ and with manifestations at an early age $[15,16]$. The genetic basis for CAD is thought to be derived from small cumulative effects of multiple common risks factors rather than a single dominant factor [17].

Some risk factors are defined to be independent from heredity: Cigarette smoking, hypertension, unfavourable levels of blood cholesterol, diabetes mellitus and advancing age [8, 18]. An additional related risk factor is obesity, particularly if abdominal. Only 15\%-20\% of all patients with CAD lack any of those risk factors [19]. Post-menopausal women run a higher risk of CAD than pre-menopausal ones. Women presenting with CAD are generally older than men [8]. Physiological factors are also shown to increase the risk for CAD [20].

\section{Ischemia}

Ischemia is defined as an imbalance between oxygen demand and supply. Plaques of the arterial vessel wall accumulate gradually and their presence induces remodelling of the arterial wall with gradual reduction of the vessel lumen. A decrease in resting blood flow is not seen until an $85 \%$ reduction in vessel area is reached [21]. Most patients that seek attention because of chest pain of possible cardiac origin experience symptoms during physical or mental stress. Tests for the detection of coronary stenoses have to be built on either physical exercise inducing ischemia, pharmacological vasodilatation inducing uneven myocardial perfusion or direct visualization of the coronary lumen. 
During exercise, oxygen demand increases three to four times compared with at rest [22] but in areas supplied by vessels with $\geq 50 \%$ stenosis the arteriolar bed is already maximally dilated and blood flow cannot increase. Potentially hypoperfused myocardium distal to a stenosis can be identified after flow redistribution induced by vasodilators [23], or by an increase in oxygen demand by an infusion of dobutamine [24].

Non-invasive examinations of patients with suspected CAD are performed at rest and during stress and are selected to imitate the situations when patients have angina. Stress is induced with exercise if the patient is able to reach an acceptable workload, $\geq 85 \%$ of their age-predicted maximum heart rate [25]. Otherwise, pharmacological agents are used. Echocardiography (Echo) has the possibility to visualize global and local dysfunction as a result of ischemia but more or less requires the use of dobutamine as a stressor to avoid respiratory motion caused by exercise [26]. Myocardial perfusion single photon emission computed tomography (MPS) and CMR use vasodilators such as Adenosine and Regadenoson as pharmacological agents, if exercise is impossible [25, 27, 28].

If the pretest probability of ischemia is low, investigations start with exercise electrocardiography (ECG). If a secondary test is necessary, local availability determines whether dobutamine stress Echo or myocardial perfusion SPECT is selected. If the pretest probability is low and the patient is unable to exercise, coronary CT may be considered. Invasive coronary angiography (ICA) is appropriate when the probability for ischemia is high, which is likely when patients have symptoms and an abnormal ECG [29].

\section{Myocardial Infarction}

Myocardial infarction is defined as cardiomyocyte death caused by an ischemic insult [29, 30]. A diagnosis of MI is dependent on the sensitivity and specificity of clinical criteria, biomarkers such as troponin and imaging studies. Infarct criteria according to guidelines have changed over time due to increasing sensitivity of biomarker analyses, e.g., troponins, which has increased the number of patients diagnosed with myocardial infarction [29].

In the atheromatous plaque, oxidized low-density-lipoprotein (LDL) is taken up by macrophages, forming foam cells. As atheromas age, $\mathrm{T}$ cells and macrophages infiltrate and as the plaque matures, a fibrotic cap develops. The plaque is prone to rupture in areas where the cap is thin and the underlying part of the plaque is infiltrated by foam cells. It is usually the rupture that triggers an occluding thrombus on the surface of the plaque, blocking blood flow [8, 30, 31]. 


\section{Magnetic Resonance Imaging}

\section{Spin and magnetization}

Clinical MRI uses physical characteristics of the hydrogen atom $\left({ }^{1} \mathrm{H}\right)$ for imaging. Positively charged hydrogen protons spin around their axis. The protons act like small magnets and are randomly oriented in space, ordinarily neutralizing local magnetic fields. When positioned in a strong magnetic field $\left(\mathrm{B}_{0}\right)$, the magnetic property of the protons are slightly more oriented in the direction of the field, giving a net magnetization vector parallel to the field. In addition to this, the magnetization vector will precess around its axis [32].

\section{Excitation}

A radio frequency pulse (RF) forces the magnetization to rotate away in a plane perpendicular to the magnetic field (excitation) [32]. The Larmor equation defines the frequency with which the protons precess, which is the frequency the RF pulse needs for excitation. This frequency can be calculated as a constant times the magnetic field strength. The constant is called the gyromagnetic ratio and is, for hydrogen protons, 42.6 megahertz per tesla $(\mathrm{MHz} / \mathrm{T})$. For a 1.5 tesla (T) scanner the frequency will be $42.6 \times 1.5=63.9 \mathrm{MHz}$. The amount of deviation from the basic field (flip angle) depends on the strength and duration of the RFpulse. If the magnetization is rotated to the transversal plane the RF-pulse is called a $90^{\circ}$ pulse $[33,34]$.

Slice selection is achieved by using a gradient coil that slightly changes the field in the slice direction. The protons affected by the gradient field will then have different Larmor frequencies. Since only protons with a frequency according to the Larmor frequency can be excited, an RF-pulse with a specific frequency will be able to excite only the selected slice [35].

When the RF-pulse is turned off, the magnetization continues to precess [32], producing an electromagnetic signal which can be detected by a receiver coil. The signal from the slice is, with orthogonal gradients, encoded in two directions, frequency and phase. The signal is collected in k-space and translated to a physical image by the Fourier transform [33, 34, 36].

\section{Relaxation}

When the magnetization vector has the direction of the magnetic field $\mathrm{B}_{0}$, the magnetization is said to be longitudinal. Transversal magnetization occurs when the net magnetization is rotated from the longitudinal plane by an RF-pulse. Immediately after the RF-pulse is turned off, the magnetization starts to recover into the longitudinal plane [32]. This is the longitudinal or $\mathrm{T} 1$ relaxation. $\mathrm{T} 1 \mathrm{is}$ defined as the time it takes for the magnetization, after a $90^{\circ} \mathrm{RF}-$ pulse, to recover to $63 \%$ of its equilibrium value in the longitudinal direction. After the $90^{\circ} \mathrm{RF}$ pulse the magnetization not only recovers in the longitudinal plane, but due to fluctuating magnetic field variation in tissue, protons will experience slightly 
different magnetic field and fall out of phase in the transversal plane. This is called transversal or T2 relaxation. T2 is defined as the time it takes after the $90^{\circ}$ $\mathrm{RF}$-pulse for the transversal relaxation to drop to $37 \%$ of its initial value [33, 34 , 37].

In T1-weighted images, tissue with long $\mathrm{T} 1$ will display a low signal and tissue with short T1 a high signal. When images are T2 weighted, tissue with long T2 will have a high signal and tissue with short T2 a low signal. The proton density weighted images will display a signal that depends on the amount of hydrogen protons present. Tissue with a high signal appears bright on the images and tissue with a low signal is dark [37].

\section{Safety}

MRI does not use radiation and is considered safe for the patients as long as there is no contraindication, such as metallic objects in the eyes, shunts and pacemakers that are not MRI compatible [37, 38]. Gadolinium (Gd) is the preferred external contrast agent used for intravenous injection. Gd is paramagnetic and causes small local magnetic fields that shorten the relaxation time of surrounding protons. In T1-weighted images, contrast enhancement is seen as a higher signal, bright on the image [39]. The use of Gd contrast media has been associated with nephrogenic systemic fibrosis (NSF) in patients with renal failure [40]. To avoid this potential complication, use of contrast media should in general be avoided if the Glomerular Filtration Rate (GFR) is lower than $30 \mathrm{ml} \mathrm{min}^{-1}$ per $1.73 \mathrm{~m}^{2}$ [41].

The GFR may be estimated from different equations related to S-creatinine and body surface area (BSA), or use calculations based on cystatin-C. The one most commonly used is the one proposed by McIntosch et al. 1928, who found a correlation between GFR and BSA, and that BSA could be normalized to $1.73 \mathrm{~m}^{2}$ [42]. For calculation of GFR, the program OmniVis $®$ (GE Healthcare) can be used [43]. OmniVis equations use plasma (serum)-creatinine (P-crea) (expressed in $\mu \mathrm{mol} / \mathrm{L}$ ), age (in years), weight $(\mathrm{kg})$, height $(\mathrm{cm})$ and gender. Two equations can be calculated with OmniVis, the Lund-Malmö and the Cockcroft-Gault equations [44].

\section{Cardiovascular Magnetic Resonance}

\section{Motion compensation}

Cardiovascular magnetic resonance sequences have to be compensated for respiratory and cardiac motion. In order to avoid respiratory motion most sequences are recorded during breath hold, with a duration of 10 to 20 . Alternatively, a navigator is used, which enables recording during free breathing [45]. Breath holding is often preferred to save time, compared with free breathing acquisitions. 
To compensate for cardiac motion, measurements are ECG gated [46]. The signal from the ECG enables triggering on the R-wave and the selection of the time delay for image collection. Most cardiac images are recorded in diastole, when the motion from the heart is minimal. Functional series (cine-loops) are recorded at several time points during the entire R-R interval [45, 47].

\section{Data sampling and acceleration}

In order to obtain an image with high signal to noise ratio (SNR), defined as the Signal Intensity (SI)/noise, k-space is sampled during several R-R intervals. Each $\mathrm{R}$-wave is followed by several excitation pulses, where each pulse encodes one line in k-space. The length of the sequence depends on how many lines in k-space are filled from each heart heartbeat and the heart rhythm of the patient. This kind of sequence is often denoted as "segmented acquisition" [48].

In patients with regular heart rhythm and successful breath holding, an image with excellent quality can be produced. Arrhythmia or difficulties holding breath result in images with, at times, extensive artefacts [49]. Such problems may be circumvented by the use of single-shot sequences. In those sequences, k-space is sampled in one R-R interval.

In functional examinations and dynamic events where contrast changes over time, high spatial and temporal resolution is necessary. Fast sequences can be used, such as Turbo fast low angle shot (Flash), Steady-state free precession (SSFP) and Echo Planar Imaging (EPI). High SNR and contrast to noise (CNR) (calculated as the SI difference between two regions/noise) favours cine SSFP for the acquisition of volumes and wall motion in CMR [50, 51]. One additional technique to decrease scan time may be to sample a reduced data set in phase. Undersampling data in phase may produce aliasing in the final images [52]. These artefacts have to be minimized and images recovered. In parallel imaging, reconstructions are made from separate coil elements in a phased array coil, where every coil element is more sensitive to the nearest volume of tissue. Knowledge about the element sensitivity makes it possible to combine undersampled data from each receiver coil into a reconstructed image minimizing artefacts [37]. The two most common techniques are reconstruction in either k-space with Generalized Autocalibrating Partially Parallel Aquisition (GRAPPA), or in the image domain with the Sensitivity Encoding (SENSE) technique [36, 37]. Data can also be shared in time where temporal interpolation estimates missing data, based on its value in both the past and in the future. It is also possible to use both spatial and temporal acceleration. A missing data point can be recovered from surrounding data points in both k-space and/or time points [36, 53].

\section{Diagnostic methods}

In one single scheduled appointment, CMR may assess morphology, function, myocardial tissue characterization and myocardial perfusion [54]. 
Reproducibility is high [55], which make CMR suitable for follow-up studies. In patients with ischemic heart disease, several aspects related to the ischemic cascade may be observed with CMR [50].

First-pass perfusion may be studied during pharmacological stress to uncover a delay of contrast wash-in with the blood that enters the coronary arteries. Images are recorded during peak stress, most often after three min of Adenosine infusion, and at rest. Areas with high perfusion display contrast enhancement and have a high signal, while areas with delayed or low perfusion have a low signal and appear dark $[56,57]$. Sensitivity and specificity has been shown to be in the range $91-94 \% / 81-88 \%$ [28].

Cine images can detect myocardial dysfunction in terms of regional and global wall motion abnormalities [50]. Cine (dynamic) images visualize motion of the heart. The beating heart is visualized when data from the same slice position are acquired at different time points during the R-R interval. For sufficient filling of $\mathrm{k}$-space, several heartbeats are required. Multiple lines in separate images (different k-space) are sampled during each heartbeat. This continues until the kspace is sufficiently filled. For the detection of wall motion abnormalities a framerate of at least 25 times per heartbeat has to be sampled.

Late gadolinium enhancement (LGE) technique visualizes myocardial injury, following MI or as a consequence of previous inflammation [50, 58, 59]. The Gd contrast medium accumulates in the extracellular space. In fibrotic nonviable myocardium, the extracellular volume increases and the contrast accumulates and washes out slowly [58,60]. About ten min after contrast injection, an inversion recovery (IR) sequence is used to detect remaining contrast in the myocardium. In an infarcted area (scar), contrast media enhances the signal. Healthy myocardium has a low signal, if the correct IR-time is chosen $[61,62]$. In patients with myocardial infarction, the LGE sequence predicts the success of revascularization, since recovery of function is most often seen in those who display a small area of LGE positivity, while an extensive scar is seen in patients who do not improve in myocardial function after revascularization [63, 64].

\section{The CMR-examination}

During CMR examination, the patient is placed in supine position and prepared with ECG (for heart triggering), a percutaneous vein catheter (if contrast media is needed), and a coil covering the chest (for the detection of the electromagnetic signal from precessing hydrogen protons). Patients wear earmuffs to protect hearing and are equipped with intercom to enable instructions from the radiographer/nurse. By using a hand-held alarm, the patients can signal discomfort. During the examination, the patient is positioned in the scanner with the heart in iso-centre (Figure 1). The diameter of the bore is often between 60-70 $\mathrm{cm}$. 

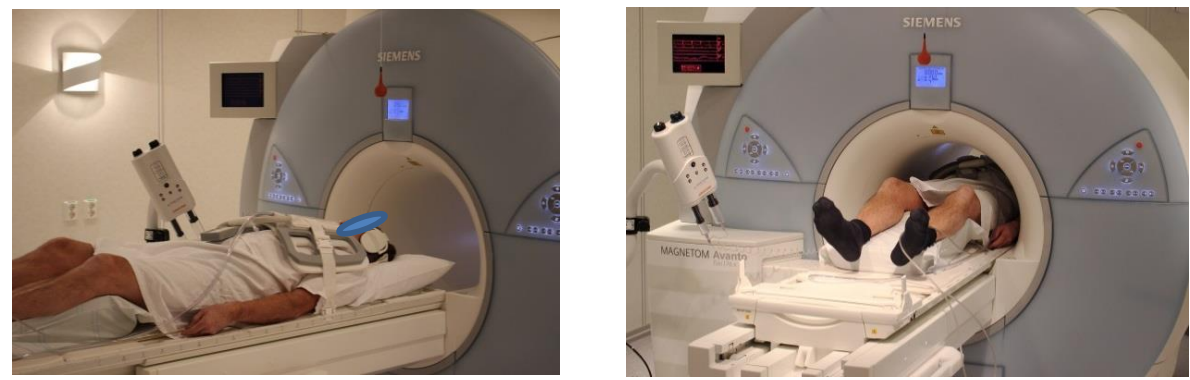

Figure 1. Patient ready for CMR examination positioned outside and inside the camera.

\section{Image quality}

High image quality improves the diagnostic accuracy of all radiological procedures [65]. Images with a high quality have been recorded without artefacts, include the area of interest in the field of view (FOV) and have a high SNR. Since some noise is always present, it is important to increase the signal in order to minimize the effect of the noise [37].

Artefacts directly related to motion are frequently seen during CMR examinations, since breath holding is difficult and ECG-triggering challenging when the heartbeat is irregular $[52,66]$. In MRI, physical constraints require compromises. As an example, signal intensity depends on the size of the image voxel. Consequently, when resolution increases, signal and SNR will decrease. Single-shot sequences sample the entire image during one heartbeat [67]. Those sequences are less sensitive to motion artefacts, but fast acquisition will always pay a price in terms of a lower SNR due to physical constraints [37]. It is debated whether single-shot sequences provide sufficient image quality to allow diagnostic evaluation.

One source of motion artefacts is restlessness due to anxiety. Törnqvist et al. found that written information had a positive impact on image quality [68]. We hypothesized this could be interesting to study in patients undergoing a demanding examination such as CMR.

In perfusion imaging, the dark rim artefact creates difficulties in the interpretation of perfusion reduction. It is recognized as a dark subendocardial band which sometimes can be mistaken for ischemia. Different theories have been invoked to explain the mechanism behind this important artefact, among them Gibb's ringing [69], signal variation during measurement [70], cardiac motion [71] and susceptibility from contrast enhancement [72]. Myocardial perfusion can be investigated with different kinds of sequences, but consensus is lacking on which to prefer $[73,74]$. All have drawbacks, such as artefacts, low SNR or not being fast enough.

The quality of CMR images can be assessed qualitatively and quantitatively [65]. Cine SSFP images, LGE images and perfusion images are evaluated separately 
based on the knowledge about the different sequences' most common artefacts. Several rating scales can be used for quality criteria, such as the presence of wrap around, respiratory ghosting, the precision of the delineation of non-infarcted and infarcted myocardium, the occurrence of artefacts and an overall evaluation of the image quality of the left ventricle, In addition, the quantitative parameters SI, SNR and CNR can be used $[65,75]$.

\section{Single photon emission computed tomography}

\section{Myocardial Perfusion SPECT}

Single photon emission computed tomography (SPECT) of the heart is frequently called myocardial perfusion SPECT (MPS). MPS is non-invasive and has a sensitivity of 70\%-80\% and specificity of 60\%-90 \% for the detection of coronary artery disease [22, 76]. A homogeneous myocardial uptake indicates normal myocardium [22, 77]. When MPS is performed with ECG-gating, evaluation of heart function in terms of volume and ejection fraction is possible [78]. Assessing wall motion also helps in the discrimination between artefacts and true perfusion deficits [76].

\section{Tracers}

Gamma-emitting radionuclide tracers are injected in the patient. For MPS imaging, thallium-201 (201TI) or technetium-99m (99mTc) can be used [22, 25].

About $4 \%$ of the injected activity of ${ }^{201} \mathrm{TI}$ is taken up in the myocardium. Thallium-201 is taken up by the myocytes, depending on a functioning sodium/potassium ATPase sarcolemmal membrane transport pump [79, 80]. It redistributes, thus allowing redistribution images to be acquired. In those images, regions of ischemic but viable myocardium will have the same uptake as normal myocardium. Areas with non-viable myocardium, that initially showed reduced uptake, will remain unchanged. The presence of redistribution allows the examination to be performed as a stress-rest study with one single injection. A major limitation for ${ }^{201} \mathrm{TI}$ is the long half-life (73 hours), which gives the patient a relatively high absorbed radiation dose [22].

In Europe, ${ }^{99 m T c}$ is the most commonly used tracer. In order for $99 \mathrm{mTc}$ to be detected in the heart, it has to be bound to a tracer molecule, either sestamibi or tetrofosmin. $99 \mathrm{mTc}$ has a rather short halflife of six hours, which reduces radiation exposure compared to thallium, but still allows imaging to be performed. About $1.2 \%$ of the dose is taken up by the myocardium [81]. Redistribution is low and for detection of viable/non-viable myocardium, stress-rest studies with separate injections have to be performed [22]. In order to reduce the radiation dose given to the patient, the rest part of the study is frequently omitted when the stress study is completely normal. In such a situation, a study at rest will not contribute to the final diagnosis. 


\section{Gamma camera}

For imaging, a gamma camera is used. In a gamma camera the gamma or x-ray photons from the radio nuclide interact with a sodium-iodine crystal. When the photon interacts with the crystal a light photon is emitted, proportional to the incoming photon energy. This energy is for ${ }^{201} \mathrm{TI} 68-80 \mathrm{keV}$ and for $99 \mathrm{mTc} 140 \mathrm{keV}$. The light is registered and converted to electrical signals, also proportional to the photon energy, by an array of photomultiplier tubes (PMT). The PMT localizes where the photons hit the crystal and an image that projects the distribution of the tracer in an object can be acquired [82, 83].

To obtain an image of high quality and high resolution, a collimator consisting of a thick sheet of lead with thousands of tiny holes is used. These allow only photons parallel to the collimator holes to reach the crystal. The sensitivity and the resolution of the images depend on the diameter of the holes and the thickness of the septa and the collimator. For each photon the energy is measured and only photons within the selected energy interval (energy window) is accepted. In this way, scattered photons are removed and only photons within the energy window contribute to the images $[82,83]$.

\section{Examination}

If patients are able to exercise to a high workload, which is usually defined as $\geq$ $85 \%$ of the age predicted maximum heart rate, European guidelines support dynamic exercise as the choice of stressor and the radiopharmaceutical is injected close to the peak exercise [81]. In patients who cannot exercise to the $85 \%$ peak heart rate limit or who are unable to exercise for other reasons, a pharmacological stressor is used. Adenosine (140 $\mu \mathrm{g} \mathrm{min} / \mathrm{kg}$ body weight) is infused over $6 \mathrm{~min}$ and the radiopharmaceutical is injected after three min [81]. Regadenoson (400 $\mu \mathrm{g}$ ) is injected over $10 \mathrm{sec}$ and the radiopharmaceutical $10 \mathrm{sec}$ later [84].

After the injection of ${ }^{201 T I}$ patients wait for 5-10 minutes before scanning, which should be completed within $30 \mathrm{~min}$. When $99 \mathrm{mTc}$ is used, imaging should begin within 30-60 min after the injection. If the study is found to be normal, there is no need to acquire perfusion images at rest. During scanning the patient is mostly in supine position with arms elevated. An ECG is applied for gating [25].

MPS is not known to induce anxiety, but very little is known about what patients experience while undergoing this examination $[1,85]$.

\section{Well-being in the context of MRI}

As many other radiologic examinations, MRI requires the full cooperation of the patient. MRI examinations are non-invasive and painless, but can nevertheless be demanding for the patient. In a radiographer survey, $72 \%$ stated that it was common that patients expressed anxiety at their MRI center [86]. During the exam, the patient is positioned in the scanner which is shaped as a tunnel in 
order to produce the best homogeneity of the magnetic field. The examined body part has to be positioned in the iso-centre of the scanner where the magnetic field has the best homogeneity [37]. The narrow tunnel is known to create problems such as nervousness, anxiety, claustrophobic feelings and uncontrolled panic in some patients [1, 87-92]. The experience of claustrophobic feelings during the MRI examination may later be generalized to other enclosed situations [90]. Due to the stressful situation, $25 \%-30 \%$ of patients complain about anxiety [88, 90], and up to $15 \%$ of all patients experience such a high level of anxiety that pharmacological sedation is necessary to conclude a successful examination [87].

During the examination a loud noise is heard, caused by vibrations of the gradient coils. To protect patient hearing, ear muffs that enable instruction and communication between the staff and the patient via intercom are used [37]. The loud noise, an experience of losing control, and the duration of the examination contribute to the feeling of anxiety [93, 94], as well as fear of pain, the "unknown" and worry about the result $[88,95]$. In addition to the circumstances mentioned above, CMR examinations are time-consuming and may last for $45-60 \mathrm{~min}$. The patient needs to remain in position on the scanner table for the entire examination and participate in breath holding up to 50-60 times [45].

Severe anxiety during MRI examinations may cause patient motion, resulting in motion artefacts [68] that decrease the diagnostic value. Studies have tried to predict patient reactions during examination $[87,96]$, but very few have asked the patients about their experience [94]. Even if manufactures have tried to improve the scanning environment, e.g., by increasing the diameter and shortening the length of the tunnel [87, 97], problems still remain and need attention $[86,94,98]$.

\section{Anxiety}

Anxiety is an emotion characterized by feelings of tension, worried thoughts and physical changes [99]. Barlow has described the central experience of anxiety as a sense of uncontrollability, largely focusing on future threats, danger, or upcoming potentially negative events. It can be characterized as a state of helplessness, because of a perceived inability to control desired results or outcomes in certain personally salient situations or contexts [100]. This feeling of uncontrollability can act as a mediator between negative events in life and anxiety [100]. This is very much like the situation patients are in. They do not know what will happen to them, questions can arise, such as: am I ill, what will happen, what kind of examinations are required, will the staff treat me well, what will the result be, is it serious? Their future is in a way out of control.

Some medical conditions are known to be associated with anxiety, like CAD. Anxiety itself increases the risk for $\mathrm{CAD}$ [101] and manifest CAD increases the risk of anxiety [102]. Anxiety can also be experienced in situations representing earlier trauma in life, for example being locked in. The patients try to cope with 
previous trauma but have a chronic inability to do so [100]. "Locked in" is a common feeling during MRI examinations.

Spielberger separated anxiety into two parts: trait anxiety as a chronic personal characteristic and state anxiety as an emotional condition varying from day to day. People with high trait anxiety more often experience higher state anxiety [103]. Even if the correlation between state and trait anxiety is high [104], there is a difference. People without anxiety in ordinary life can feel anxiety in situations when they experience a threat [103].

Anxiety disorders are among the most prevalent psychiatric disorders. The 12month prevalence for men is $7.8 \%$ and for women $16.3 \%$ [105]. The burden is heavy, both for the individual and for society. Symptoms of anxiety can at times be mild, with an onset associated with stressful situations in life and improving without specific treatment [106], to a full-blown chronic disabling disease. Several instruments are used to measure anxiety, for example: Competitive State Anxiety Inventory (CSAI) [107], Spielberger State and Trait Anxiety Inventory (STAI-S and STAI-T) [103], and the Hospital Anxiety and Depression scale (HAD) [108]. These instruments measure general anxiety, but sometimes we want to measure what Spielberg refers to as "state anxiety", e. g., when being in an MRI scanner. This situation is known to be anxiety ridden [1, 87-92] for some patients, but instruments that measure the experience and feelings during examinations are lacking.

\section{How to psychologically prepare the patient for the MRI study}

Information about the scanning procedure tries to avoid or reduce stress and anxiety during the examination $[6,109]$. Prior to a scan, many, but not all, patients feel a need for extended information [1]. In a previous study, $71 \%$ wanted additional information about their examination [109]. Information requested by patients before MRI concerned the narrow environment, the loud noise and the duration of the examination, which is substantially longer than other radiological examinations [95]. There is a relation between the patient's understanding and compliance, where well-informed patients follow instructions better [7]. There is also a positive correlation between information given and patient satisfaction [7, 110]. In this situation, the way information is given and received is crucial. All patients do not understand the purpose of information since they may have difficulties understanding and remembering [7, 111]. Guidelines cannot foresee all situations in which communication is necessary. To improve patient understanding, information has to be easy to understand by using simple language without medical terminology [7, 112]. Information is important and the experience of undergoing a high-technology imaging procedure produces a unique experience for each patient. Myths and stories can have a negative effect $[113,114]$, and bad experiences can have a negative effect on future examinations [115]. 
Some studies have evaluated the use of extended information and support during MRI examinations. Detailed information by a radiologist (10 min) or psychologist (45 min) before examination resulted in less anxiety compared to patients who received standard information [116, 117]. Extended written information has shown various results in patients undergoing MRI, with both significantly lower anxiety in the group who received designed instructions before MRI compared with the one who received standard information [110], but also no difference [68]. Even if no difference was detected between groups in the feeling of anxiety, there was less motion artefact in the images of the patients in the experimental group [68]. One study suggest that the effect of oral information can be detected in the plasma levels of cortisol and prolactin as well as the level of anxiety measured with questionnaires [98].

Video information has been used pre-surgery to reduce preoperative anxiety and postoperative morbidity with positive results. Lower anxiety levels have been measured in patients who received video information compared with control groups [118-120]. Some patients benefited from a lower level of anxiety up to one year after bypass surgery [120]. Even cortisol excretion was found to be lower in the experimental group after video information, compared with the control group in patients undergoing hip replacement surgery [118].

It is known that MRI can cause intense anxiety in some patients [1, 87-92]. Extended written information has not shown univocal results. Video information before surgery has resulted in decreased anxiety. An important question to answer is if the use of video information could contribute to a better experience for this group of patients.

\section{Rationale}

Cardiovascular disease is the most common cause of death in Europe [4]. With a growing and ageing population, and an increasing prevalence of obesity and diabetes, the number of patients with cardiovascular disease is expected to increase further [121]. For an optimal result of medical treatment, early diagnosis is of great importance. In addition to patient history, various imaging methods such as CMR can be used for diagnosing symptoms, as well as for screening those with a high cardiovascular risk. With an increasing number of patients, there is a risk that the time given to each patient decreases. Still, the patients have to be treated and examined in an optimal way. They have to be well informed which gives them the possibility to know what is expected of them and how to cooperate. During examination, the correct sequences have to be chosen based on the patient's possibilities, in order to optimize the diagnostic properties. These sequences have to be evaluated and one way to overcome the need for experienced readers is to use quantitative evaluations when possible. 


\section{AIMS}

\section{The overarching aim of this thesis was}

- to evaluate image quality in cardiac MRI with respect to the sequences employed and the influence of atrial fibrillation, myocardial perfusion and the impact of patient information on measured anxiety.

- to study patients in relation to magnetic resonance imaging with the goal of improving their care

\section{The specific aims of the studies were as follows}

\section{Paper I}

- to assess differences in image quality and estimated infarct size between two MRI scar sequences IR-FGRE (segmented) and SS-SSFP (single-shot), in patients with chronic myocardial infarction and difficult-to-image permanent atrial fibrillation.

Paper II

- to study two CMR first-pass perfusion sequences, GRE-EPI (gradient echo-echo planar imaging) and SSFP (steady state free precession) in terms of image quality and final diagnosis, with the result from the MPS stress study as reference.

Paper III

- to develop and validate a new instrument measuring patient anxiety during Magnetic Resonance Imaging examinations, MRI-AQ (Magnetic Resonance Imaging-Anxiety Questionnaire).

Paper IV

- to evaluate the effect of video information given before CMR on patient anxiety.

- to study patient experience of CMR and MPS.

- to evaluate the effect of extended video information on image quality. 


\section{METHODS}

\section{Design}

This thesis is based on four publications (I-IV), designed as experimental crossover (I), experimental controlled clinical trial (II), psychometric cross-sectional (III) and prospective intervention (IV) see table 1.

\section{Participants}

This thesis consists of four independent data collections with four different samples of participants and collection times (Table 1). The participants were $\geq 18$ years and had primarily cardiac problems except for those referred for MRI of the spine in study III. For inclusion and exclusion criteria in the different studies see table 1. There was no recruitment from the general population.

\section{Study I}

Twenty patients, mean age 75 years, with permanent atrial fibrillation and pathological Q-waves on the resting ECG were identified at two medical clinics (Table 1). Additional inclusion criteria were myocardial infarction verified with chest pain, typical serial ECG changes and/or elevated levels of either Troponin $\mathrm{T}$ or creatinine kinase MB in at least two blood samples during hospitalization no later than 6 weeks prior to the CMR examination. During the CMR examinations all were in atrial fibrillation. No patients were excluded due to technical failure or poor image quality.

\section{Study II}

Sixty patients, mean age 64 years, referred for MPS for myocardial ischemia were included in the study which was collected in two cohorts, separated by time. The ages were similar, but the relative number of men and women differed with $43 \%$ and $33 \%$ females in the two groups respectively. Thirty patients were investigated with a steady-state free precession (SSFP) sequence and 30 patients were investigated with a gradient echo-echo planar imaging (GRE-EPI) sequence (Table 1). Of the 67 patients originally included one was excluded due to lack of two venous access lines. Four were excluded because of claustrophobic feelings, one for technical reasons and one patient because of arrhythmia.

\section{Study III}

Two-hundred and forty-seven patients, mean age 55, referred for MRI of either the spine $(\mathrm{n}=193)$ or the heart $(\mathrm{n}=54)$ were included in the study. Their ages were similar, but the gender distribution differed, with $63 \%$ women in the spine group and $46 \%$ women in the heart group. 
Eight-hundred and eighty-one patients were asked to participate. Of those, 781 were referred for MRI of the spine and 100 for MRI of the heart. Two hundred and forty-seven patients (28\%) accepted to participate and answered the questionnaires. In the spine-group the participation rate was $24 \%$ and in the heart-group 54\% (Table 1).

\section{Study IV}

One-hundred and forty-eight patients, mean age 55 years, from the waiting list referred for either CMR $(n=97)$ or MPS $(n=51)$ were included in the study. Of the 214 patients who were invited to participate, 150 patients accepted, two were prematurely interrupting the examination (one in each CMR group), giving a response rate of $69 \%$. Patients who underwent CMR were randomized to either the intervention (CMR-video $n=49$ ) or the control group (CMR-standard $n=48$ ). The MPS ( $n=51$ ) patients were older, mean 64.5 years, than those referred for CMR-standard, mean 49.4 years $(\mathrm{p}=<0.001)$. The distribution of gender differed: CMR-standard had 54\% female, CMR-video 29\% and MPS 27\%. The differences were statistically significant, with CMR-standard/CMR-video $(p=0.009)$ and CMR-standard/MPS ( $\mathrm{p}=0.008)$ (Table 1). 
. 幽焉

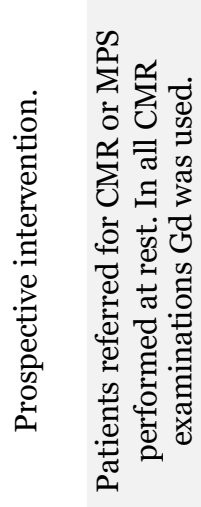

'ृ્0

मु

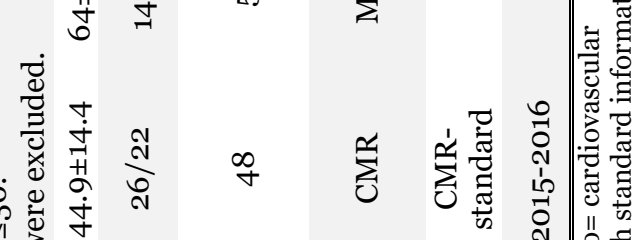

(2)

卷.

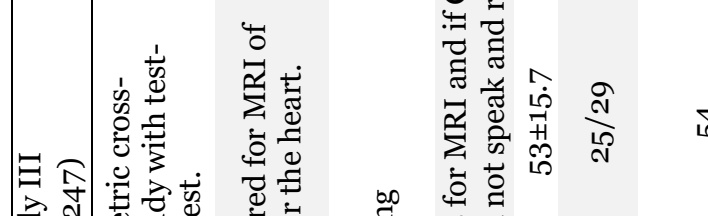

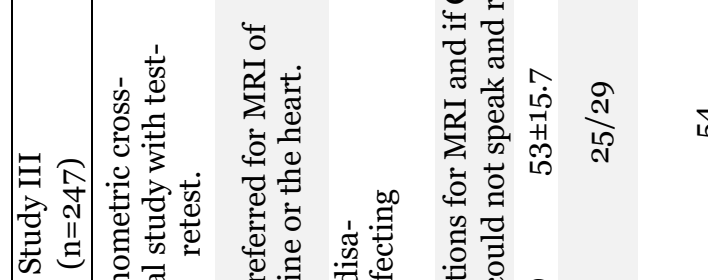

歪氙

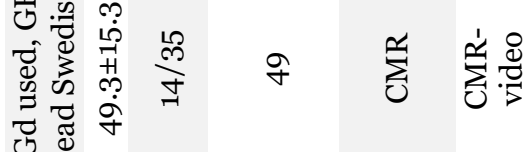

10

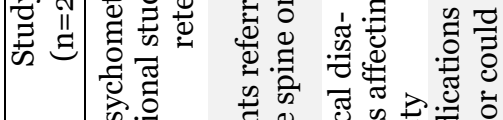

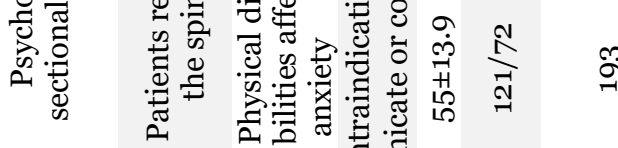

$\underset{-1}{2}$ 홍

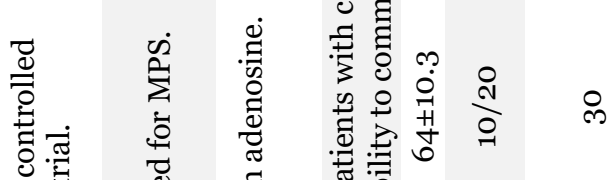

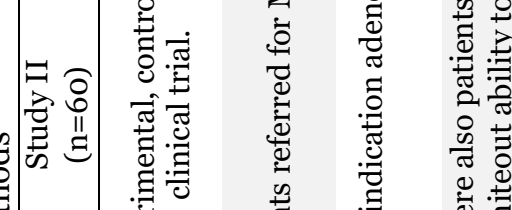

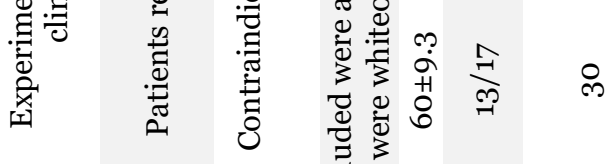

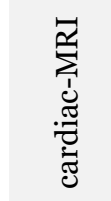

承

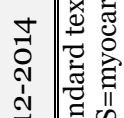

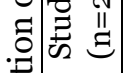

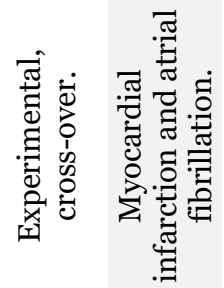

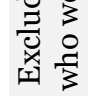

望

กิ

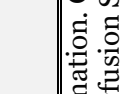

造

西

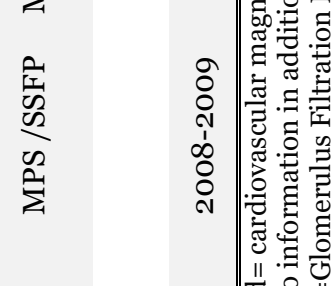

起

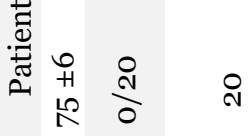

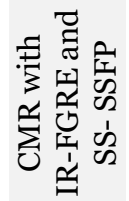

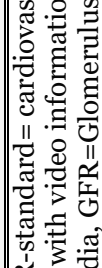

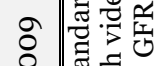

文

กิ

웜

守

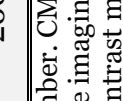

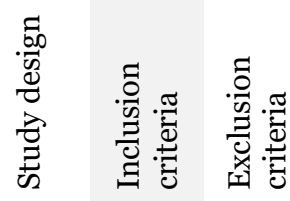

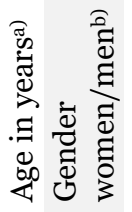

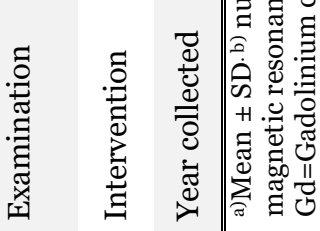




\section{Data Collection}

\section{MRI (I\&II)}

Two scanner types were used: Siemens Magnetom Symphony and Siemens Magnetom Avanto, both operating at $1.5 \mathrm{~T}$ field strength and manufactured by Siemens Healthcare, Erlangen, Germany.

The patients were examined in supine position. ECG was used to monitor heart rate and rhythm and for triggering. All patients had a percutaneous vein catheter for contrast injection and in study II they had an additional catheter in the opposite arm for the injection of adenosine. For signal detection a body matrix coil, consisting of several independent coils, was positioned over the patient's chest. This was used in connection with the spine matrix coils.

Before examination all patients were asked about their age, gender, previous percutaneous coronary intervention (PCI), coronary artery bypass graft (CABG) surgery, and medications.

\section{Study I}

Cine images were acquired, using a SSFP sequence, in the apical longaxis, (the two-, three- and four-chamber views) and in short axis view covering the left ventricle (LV). For LGE two sequences were used: the single shot SSFP (SS-SSFP) and the segmented inversion recovery-fast gradient echo (IR-FGRE) sequences. For technical data see table 2. Both LGE sequences were positioned in the same planes as the cine images. LGE images were recorded ten minutes after the injection with $0.2 \mathrm{mmol} \mathrm{Gd} / \mathrm{kg}$ bodyweight [59], Gadopentate dimeglumine 0.5 $\mathrm{mmol} / \mathrm{ml}$ (Magnevist, Schering Nordiska AB, Järfälla, Sweden). Images were acquired in end diastole. The SS-SSFP sequence was acquired at the end of expiration and breath holding was not necessary. Both sequences were recorded in all patients. In every other patient the SS-SSFP sequence was acquired first.

Table 2. Parameters used in Study I.

\begin{tabular}{llll}
\hline & Cine & SS-SSFP & IR-FGRE \\
\hline TR & $43 \mathrm{~ms}$ & $10.8 \mathrm{~ms}$ & $12 \mathrm{~ms}$ \\
TE & $1.3 \mathrm{~ms}$ & $1.26 \mathrm{~ms}$ & $5.4 \mathrm{~ms}$ \\
FA & $72^{\circ}$ & $50^{\circ}$ & $30^{\circ}$ \\
BW & $930 \mathrm{~Hz}$ & $1180 \mathrm{~Hz}$ & $140 \mathrm{~Hz}$ \\
Slice & $8 \mathrm{~mm}$ & $8 \mathrm{~mm}$ & $8 \mathrm{~mm}$ \\
Matrix & $192 \times 156$ & $192 \times 108$ & $256 \times 160$ \\
\hline \hline
\end{tabular}

Repetition Time $=$ TR, Echo Time $=$ TE, Flip Angle $=$ FA, Band Width $=$ BW. 


\section{Study II}

Blood pressure was measured before the examination for baseline reference. For stress perfusion adenosine (140 $\mu \mathrm{g} \mathrm{min} / \mathrm{kg}$ body weight) was infused after the patients had abstained from caffeine for $24 \mathrm{~h}$ [122]. During adenosine infusion patients were placed outside the scanner for observation. After three min adenosine infusion, the radiotracer, $99 \mathrm{mTc}$ tetrofosmin, was given (for the MPS study), followed by $8 \mathrm{ml} \mathrm{Gd}$, Gadopentate dimeglumine $0.5 \mathrm{mmol} / \mathrm{ml}$ (Magnevist; Bayer Schering Pharma, Berlin, Germany) at a rate of $4 \mathrm{ml} / \mathrm{sec}$. Under contrast injection three perfusion short axis images, positioned at the base, mid and apex of the LV, were recorded, while the adenosine infusion was running. Thirty of the 60 participants were examined with a SSFP sequence and 30 with a GRE-EPI sequence, and the result was compared with MPS as reference. Technical data are given in table 3. Ten min after stress, perfusion at rest was recorded using the same parameters as for stress. For LGE images a third injection was given aiming at a total dose of $0.2 \mathrm{mmol} / \mathrm{kg}$ bodyweight [59] (max dose $30 \mathrm{ml}$ ). Cine images were acquired immediately after contrast injection followed by LGE images approximately 15 minutes after contrast. MPS was performed about 60 min after the injection of the radiotracer.

Table 3. Parameters used in Study II

\begin{tabular}{lll}
\hline & SSFP & GRE-EPI \\
\hline TR & $172.7 \mathrm{~ms}$ & $146.95 \mathrm{~ms}$ \\
TE & $1.11 \mathrm{~ms}$ & $1.26 \mathrm{~ms}$ \\
FA & $40^{\circ}$ & $20^{\circ}$ \\
BW & $1359 \mathrm{~Hz}$ & $1628 \mathrm{~Hz}$ \\
Slice & $8 \mathrm{~mm}$ & $8 \mathrm{~mm}$ \\
Matrix & $60 \times 160$ & $102 \times 128$ \\
\hline \hline & Repetition Time = TR, Echo Time = TE, Flip Angle = FA, \\
Band Width = BW.
\end{tabular}

\section{MRI analysis (I\&II)}

\section{Study I}

The short axis stack of cine images was segmented in diastole and systole and LV volumes were measured. Infarct size was measured on the LGE short axis images where the papillary muscles were included in the LV size/infarction if they were attached to the myocardium at the particular site.

Visual assessment of the LGE image quality was performed in terms of the delineation of non-infarcted and infarcted myocardium and the presence of motion and other artefacts. Finally, an overall quality score of the left ventricle was assigned. All aspects were evaluated on a five point rating scale with five being the highest score [75]. The rating scale corresponded to the following verbal expressions: "very good", "good", "moderate", "poor" or "very poor". 
Cine images, in short axis view, were evaluated visually in two aspects, one regarding the occurrence of artefacts and the other was an overall evaluation of blurring from irregular displacement of the $\mathrm{LV}$ wall. The same five-point rating scale was used with 5 being the highest rating. The quality of the LGE and cine images was evaluated by two observers and averaged. Both observers were blinded to which LGE sequence had been used.

SI, SNR and CNR were determined on images from the LGE sequences, SS-SSFP and IR-FGRE. To calculate SI, regions of interest (ROI) were placed in normal (myo) and infarcted myocardium (inf). A ROI of at least $300 \mathrm{~mm}^{2}$ was used in the blood pool. Noise was defined as the standard deviation (SD) of the SI measured in the air outside the patient. The SNR was calculated by dividing SI by the noise. The CNR value for the infarcted myocardium compared with the normal myocardium was calculated as $\left(\mathrm{SI}_{\text {inf }}-\mathrm{SI}_{\mathrm{myo}}\right) /$ noise. The $\mathrm{CNR}$ value for infarcted myocardium compared with the blood in the ventricle was ( $\mathrm{SI}_{\text {inf-SI }} \mathrm{Slood}_{\text {bloise. }}$.

\section{Study II}

The perfusion studies were evaluated qualitatively and semi-quantitatively. A qualitative, visual evaluation was done to assess if there was a delay in the washin of contrast medium. If there was a delay at stress but not in the rest images, ischemia was deemed to be the likely cause. If the delay was four beats or less and affected a shallow depth of the $\mathrm{LV}$ wall, an artefact was considered to be the cause [123]. Diagnostic confidence was rated on a four-point scale: (1) normal with high confidence, (2) normal with low confidence, (3) pathologic with low confidence and (4) pathologic with high confidence [124]. A qualitative evaluation of firstpass perfusion was performed by an experienced reader of CMR who was blinded to the MPS result. LGE was used to identify scar areas. An LGE-positive segment was always considered pathologic [125, 126] (Figure 2).

A semi-quantitative analysis was performed to measure the slope of the signal increase in the myocardium during contrast injection using "Argus dynamic signal" from Siemens Healthcare. The three slices were automatically divided into 6 segments each (a total of 18 segments). The epicardium and the endocardium were manually outlined, excluding high signal from blood pool and from epicardial fat surrounding the LV. The slope (wash-in curve) of the inflow signal was calculated between the foot and the peak of the signal intensity curve (Figure 3). 


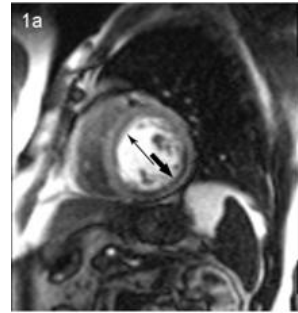

$2 \mathrm{a}$

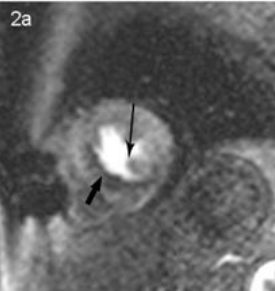

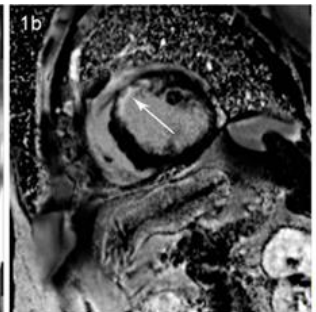
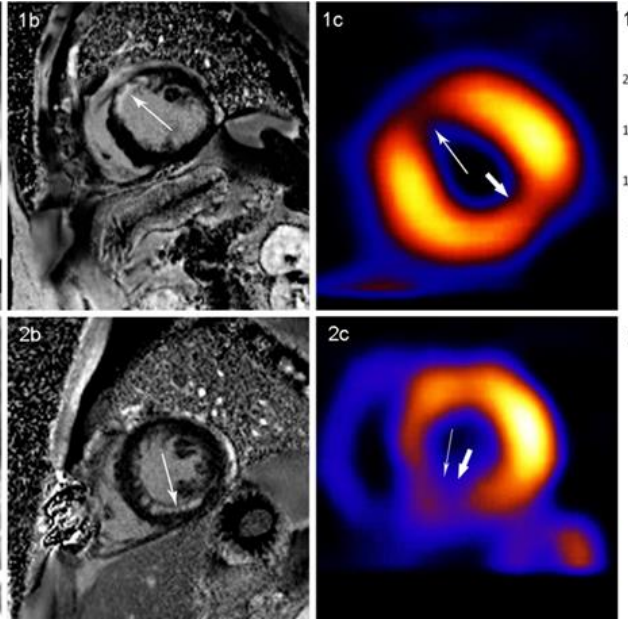

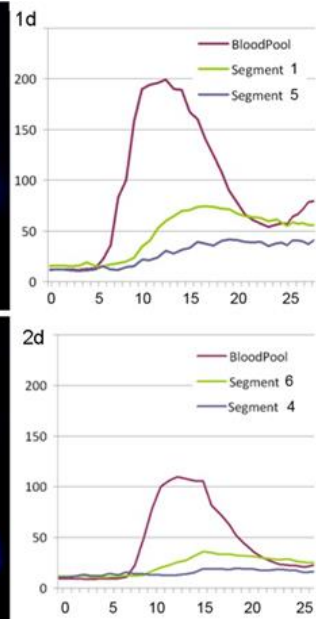

Figure 2. Composite image of two patient studies with ischemia and myocardial scar, SSFP in 1 (upper row) and GRE-EPI in 2 (lower row). Perfusion with SSFP-sequence (1a), anteroseptal scar visualized with LGE-sequence (1b), corresponding MPS image (1c) and contrast wash-in curves (1d). The bloodpool curve was annotated red, a pathologic segment blue and a normal segment green. In the lower row, perfusion is depicted with the GRE-EPI sequence (2a), an inferoseptal scar in 2b, MPS image $2 c$ and wash-in curves $2 \mathrm{~d}$, with annotation of the curves in $2 \mathrm{~d}$ as in $1 \mathrm{~d}$. Segment numbers according to SCMR. Scar is indicated by thin arrows and ischemia by thick arrows. In wash-in curves, MRI contrast signal intensity is depicted on the $\mathrm{y}$-axis and time (sec) on the $\mathrm{x}$-axis.
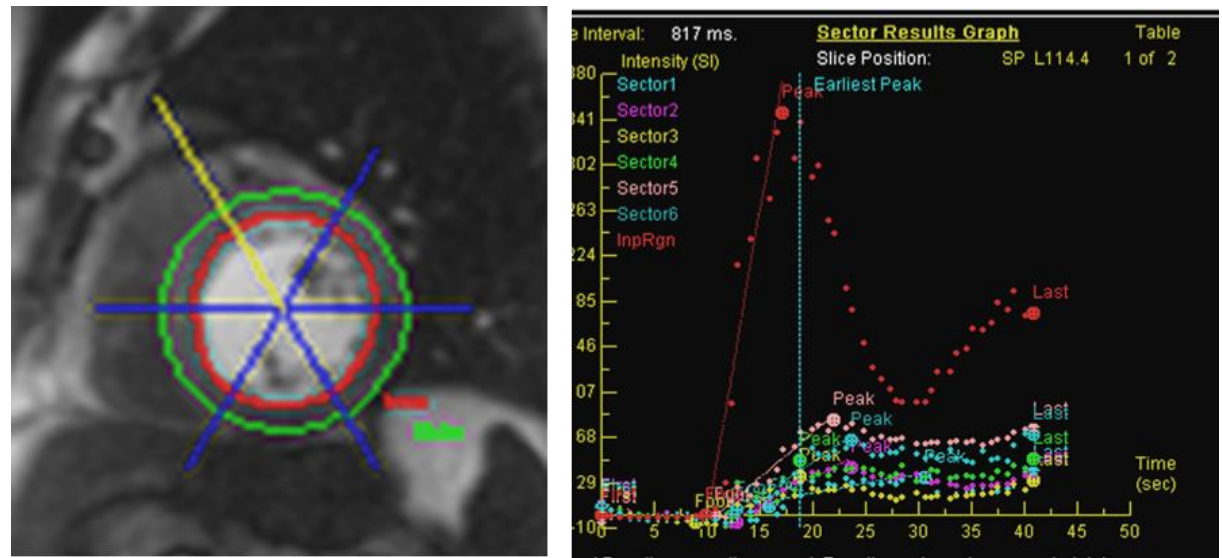

Figure 3. Endocardial and epicardial segmentation (left). Wash-in curves for the blood pool and the 6 segments in one slice (right).

SNR and CNR were calculated in the anterior segment of the basal LV when healthy and in all segments with ischemia, before (lowest signal) and after (highest peak signal) contrast injection. Noise was the SD of SI from air outside 
the patient. SNR was calculated as SI/noise. CNR was calculated for the contrast enhanced myocardium during perfusion as signal intensity difference divided with noise (SI $\left.\mathrm{Syocard}_{\text {perfusion}}{ }^{-} \mathrm{SI}_{\text {Myocard baseline}}\right) /$ noise.

\section{MPS (II)}

MPS imaging was started 60 minutes after the injection of the radiotracer, 5.7 $\mathrm{MBq}$ 99mTc tetrofosmin/kg bodyweight was given i.v. (max $570 \mathrm{MBq}$ ) (Myoview тM, GE Healthcare Medi-Physics, Inc, Arlington Heights, IL, USA). A dualdetector gamma camera (E. Cam; Siemens Medical System Inc, Hoffman Estates IL, USA) equipped with a high resolution collimator was used. Thirty-two views were acquired in steps of 2.8 degrees per detector. Acquisition time/angle was 30 s. and a $19 \%$ window was asymmetrically placed (129-155 keV) on the $140 \mathrm{keV}$ peak. A 64 x 64 matrix was used.

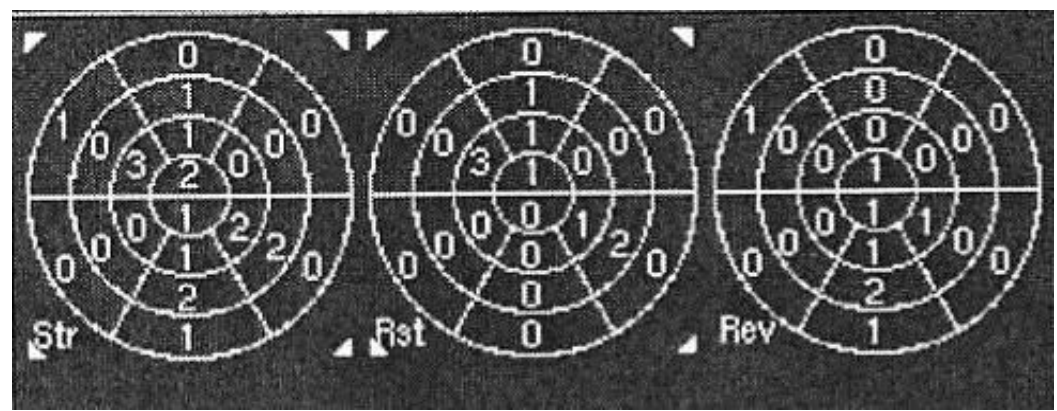

Figure 4. Three schematic images of the heart, during stress (left), at rest (mid) and their difference indicating reversibility (right). Stress scores from QPS software, $>2$ is considered pathological.

\section{Analysis of MPS (II)}

Non-gated acquisition files were reconstructed using filtered back-projection, prefiltered with a Butterworth filter (cut-off $0.8 \mathrm{~cm}^{-1}$, order 10), (Hermes Medical Solution, Stockholm, Sweden). The images were realigned into short axis and long axis presentations. The short axis stack was analysed with QGS-QPS Quantitative Perfusion SPECT (Cedars-Sinai Medical Centre, Los Angeles, CA, USA). Stress perfusion images were divided into 20 segments. The two apical segments were excluded since the apical images are not available on the perfusion CMR. A stress score was given according to reference standard incorporated in the QPS software, being based on segmental differences in signal intensity in a reference population. The scores were: (o) normal, (1) probably normal, (2) probably diseased and (3 and 4) definitely diseased (Figure 4)

Visual assessment was performed by an experienced nuclear physician, who was blinded to the CMR-perfusion result, using both stress and rest images. 


\section{Measures (III \& IV)}

Permission was granted by the publisher to use the CAQ and HAD questionnaires. For MRI-FSS and STAI-S, published public versions were used.

\section{Cardiac Anxiety Questionnaire (CAQ) (IV)}

The CAQ consists of 18 statements divided into three factors assessing heart focused anxiety [127]. The factors are fear (eight statements), avoidance, and attention (five statements each). The statements are rated on a five-point scale, ranging from o ("never") to 4 ("always"), where a higher score indicates more intense heart focused anxiety. The total score ranges from o to 72.

\section{Hospital Anxiety and Depression scale (HAD) (III \& IV)}

The HAD measures general anxiety and depression $[108,128]$. It consists of two factors with seven questions about anxiety and seven about depression. Both scales are rated on a four-point scale where a higher score indicates a more intense level of anxiety and depression. The possible score ranges between $\mathrm{o}$ and 21 for each scale

\section{Magnetic Resonance Imaging Fear Survey Schedule (MRI-FSS) (III \& IV)}

The MRI-FSS consists of nine statements from the Fear Survey Schedule [129], defined by Lukins et al. [130]. These nine statements deal with fear in situations related to MRI examinations and were developed to predict fear during such examinations [96]. Patients rate the statements on a seven-point scale ranging from "no fear at all" to "terrified". Higher scores predict more intense level of anxiety during the examination. The total score ranges between 9 and 63 .

\section{Spielberger State Anxiety Index (STAI) (III \& IV)}

The STAI consists of two separate scales with 20 items each, measuring state (situational) and trait (baseline) anxiety [103, 131]. In the present study, only the state anxiety scale, which measures the anxiety patients experience at a particular moment, was used, denoted STAI-S. Patients rate their feelings on a four-point scale ranging from "not at all" to "very much", with a total score range between 20 and 80. High scores imply a more intense level of anxiety

Two study specific questions (III \& IV)

In the single item questions the participants were asked to rate their feeling of anxiety and worry during examination. They were rated on visual analogue scale ranging from $1=$ "very good" to $10=$ "very bad".

\section{The staff (III \& IV)}

Staff was asked about patient sedation and if the patients entered the tunnel head or feet first. They also ranked how they judged patient feelings of anxiety and worry during examination. The staff responses were rated on a visual analogue scale ranging from $1=$ "very good" to $10=$ "very bad", similar to the scale used by the patients. 
Magnetic Resonance Imaging Anxiety Questionnaire MRI-AQ (IV)

The MRI-AQ measures anxiety during MRI examinations [132]. It involves 15 items, divided in two factors. One factor is anxiety, consisting of 12 items and one is relaxation, 3 items. The statements are rated on a four-point scale ranging from $1=$ "not at all" to 4 ="very much". The score ranges from 15 to 60 , where a higher score indicates a higher level of anxiety.

\section{Information (IV)}

The patients were asked to rate their impression of the information on a visual analogue scale ranging from $1=$ "very good" to $10=$ "very bad".

\section{Development of Magnetic Resonance Imaging-Anxiety Questionnaire (MRI-AQ) (III)}

\section{Scale development}

The first step towards creating an instrument with high validity is to ensure that the correct questions are asked. With permission from the authors [94], 22 items were constructed based on the result of a hermeneutic phenomenological study in which 19 patients were interviewed about their experience during MRI examinations. The 22 items were discussed by an expert group that decided to exclude three items. Two of the excluded questions dealt with patient thoughts during the examination. One was unclear in terms of difficult choice of statements. Content validity was evaluated with the help of the content validity index (CVI). CVI was rated by a group of seven health care professionals. The items were judged on a four-point scale ranging from $1=$ not relevant, 2=somewhat relevant, 3 =quite relevant and 4 =highly relevant. The answers were then dichotomized to $\mathrm{O}=$ not relevant and $1=$ relevant. CVI was evaluated on item level (I-CVI): the number of experts who rated an item as relevant was divided by the number of experts, and the scale level (CVI-S) calculated as the average proportion of items rated as relevant [133].

After discussion in the expert group, we decided to use a four point rating scale: 1 ="not at all", 2="somewhat", 3= "moderately" and 4="very much". The use of the statements can be illustrated by "I wanted to come out" which was rated " 1 " if the patient did not agree and " 4 " if they did. Reversed items in the instrument had to be inverted before calculation, to allow a high score to indicate a higher degree of anxiety.

\section{Psychometric testing}

Patients who participated in the study responded to questionnaires after scanning was completed. For the test-retest part, 111 patients answered the questionnaire once more, one week after the examination.

Missing data, score distribution, ceiling and floor effects were evaluated. The homogeneity of the scale, which means how each item correlates with the sum of the others, was calculated with item-total correlation adjusted for overlap. An $r \geq$ o.30 was defined as an acceptable level [134]. 
To explore underlying structures, an exploratory factor analysis using the unweighted least square method was used. Before the factor analysis the correlation between the items was evaluated with Bartlett's test of sphericity $\left(X^{2}(153)=2058.8, \mathrm{p}<0.001\right)$ and Kaiser-Mayer-Olkin measure of sampling adequacy (0.896), indicating a satisfactory correlation between the items. The number of factors were selected using the Kaiser criterion $>1[135,136]$ and confirmed by Horn's parallel analysis, using 95th percentile and 500 iterations [137].

Communality values were inspected to evaluate how much of the variance in each variable was explained by the extracted factors. Items with low communality values $(<0.20)$ and/or factor loadings $(<0.40)$ were excluded.

Cronbach's alpha measures the internal consistency, meaning the extent to which the items are interrelated. A Cronbach's $\alpha>0.70$ is rated acceptable for psychometric scales, $>0.80$ good and $>0.90$ excellent. If alpha exceeds 0.90 it can also be used for individual assessment [135].

Criterion-related validity was calculated between the instruments MRI-AQ, STAIS, MRI-FSS, HAD and the two study-specific single items about experiences and worries. Known-group validity evaluates the sensitivity of the new instrument to distinguish between different groups of patients. We hypothesized that MRI-AQ correlated higher with instruments measuring anxiety than those measuring depression and that it could distinguish between patients examining the heart or the spine.

\section{Procedure for the intervention study (IV)}

All CMR studies were performed with contrast injection. All examinations were performed at rest, without use of pharmacologic or physical stress.

The participants responded to questionnaires before the examination and immediately after. A one-week follow-up was performed to evaluate the intensity of the memory of the experience and anxiety of the examination (Table 4). 
Table 4. Flow chart study IV

\begin{tabular}{|c|c|c|c|c|c|c|}
\hline \multirow{2}{*}{$\begin{array}{l}\text { Appointment } \\
\text { letter }\end{array}$} & \multicolumn{5}{|c|}{$\begin{array}{c}\text { Day of examination at the department of } \\
\text { Radiology and Clinical Physiology }\end{array}$} & \multirow{2}{*}{$\begin{array}{l}\text { At home } \\
\text { one week } \\
\text { after the } \\
\text { examination }\end{array}$} \\
\hline & Department & $\begin{array}{c}\text { Before } \\
\text { examinati } \\
\text { on }\end{array}$ & $\begin{array}{c}\text { Interven- } \\
\text { tion } \\
\text { CMR }\end{array}$ & $\begin{array}{l}\text { Examina } \\
\text { tion }\end{array}$ & $\begin{array}{c}\text { After } \\
\text { examination }\end{array}$ & \\
\hline $\begin{array}{c}\text { Together with } \\
\text { the } \\
\text { appointment } \\
\text { letter, } \\
\text { information } \\
\text { about the study } \\
\text { and invitation } \\
\text { to participate }\end{array}$ & $\begin{array}{l}\text { Informed } \\
\text { consent. } \\
\text { For CMR: } \\
\text { Randomized: } \\
\text { intervention } \\
\text { or control }\end{array}$ & $\begin{array}{l}\bullet \text { History } \\
\bullet \text { CAQ } \\
\bullet \text { HAD } \\
\bullet \text { MRI-FSS } \\
\bullet \text { STAI-S }\end{array}$ & $\begin{array}{l}\text { Video or } \\
\text { no video }\end{array}$ & $\begin{array}{l}\text { CMR or } \\
\text { MPS }\end{array}$ & $\begin{array}{l}\text {-MRI-AQ } \\
\text {-STAI-S } \\
\text {-Checklist } \\
\text { information } \\
\text {-Checklist } \\
\text { personal }\end{array}$ & $\begin{array}{l}\bullet \mathrm{MRI}-\mathrm{AQ} \\
\bullet \mathrm{HAD} \\
\bullet \mathrm{CAQ} \\
\cdot \mathrm{MRI}-\mathrm{FSS}\end{array}$ \\
\hline
\end{tabular}

$\mathrm{HAD}=$ Hospital Anxiety and Depression scale, $\mathrm{CAQ}=$ Cardiac Anxiety Questionnaire,

STAI-S = Spielberger State Anxiety Index -State, MRI-FSS = Magnetic Resonance Imaging Fear

Survey Schedule, MRI-AQ = Magnetic Resonance Imaging- Anxiety Questionnaire

Checklist information =the participants ranked information on a 10-point scale, Checklist personnel $=$ the staff informed about the sedative given and ranked how they perceived the patient's experience and worry throughout the examination. $\mathrm{CMR}=$ Cardiovascular Magnetic

Resonance imaging. MPS=Myocardial Perfusion SPECT.

\section{Standard patient information regarding CMR and MPS}

The letter scheduling the appointment included information about the examination procedure, CMR or MPS. The text for CMR explained how patients are positioned in the MRI-scanner, that they had to be completely immobile for parts of the study, and that a loud knocking noise would be heard during the examination. The MPS group received standard text-based information about having a light breakfast, explaining the injection of an isotope and how positioning in the gamma camera would be carried out. All groups received oral information throughout the examinations.

\section{Video or standard information}

If the patient received standard information or video information was based on the order in which the patients appeared in the outpatient scheduling list. Assigning the type of information was executed as follows: Each patient was given a study number. In the order they appeared for scanning, every other patient was allocated to either the intervention group receiving video-information in addition to standard information (CMR-video), or to the control group which received the standard text-based information (CMR-standard) only.

\section{Intervention}

A five-minute video where an actor plays the role of the patient was produced demonstrating the whole procedure of CMR. The video begins with the radiographer bringing the patient into the scanner suite, asking about contraindications. The video shows patient preparation with the application of ECG leads, a percutaneous vein catheter, a surface coil on the chest for imaging, 
ear muffs and an alarm. The need for immobilization and breath holding is repeated. The video ends with the patient leaving the CMR-unit.

\section{Image quality}

Image quality was evaluated in terms of motion artefacts, which are heavily influenced by patient cooperation. Three observers blinded towards the information given to the patients rated image quality on cine images of the three long axis and all short axis slices. Motion artefact was present if blurring (arrhythmia excluded) was seen in at least two slices. In a secondary step, a patient was considered to have motion artefact if determined by at least two of the observers.

\section{Statistics}

Descriptive data was used to describe the characteristics of the participants in all studies. For parametric data mean $(\mathrm{m}) \pm$ standard deviation (SD) and percentage (\%) was used. Nonparametric data was described with median (med) and interquartile range (IQR). Student's t-test was used for evaluation of statistical significance of parametric data, Mann Whitney U-test for data on ordinal level and Fischer's exact two tailed test on a nominal level.

\section{Study I}

Wilcoxon pairwise signed rank test was used for comparison between the SSSSFP and the IR-FGE sequences, based on ordinal data.

Interobserver variability was expressed as standard error of a single determination $\left(\mathrm{S}_{\text {method}}\right.$ ) using the formula proposed by Dahlberg [138]. F-test was used to compare $S_{\text {method }}$ (comparison of variance) between the two sequences. Kappa was used to evaluate interobserver agreement.

Since the volumes measured were reasonably normally distributed the difference between the two sequences was evaluated with two-sided t-test for paired observations.

A correlation coefficient between the two sequences was calculated regarding myocardial volume, infarct volume and infarct extent.

\section{Study II}

Intraclass correlation was used for evaluation of interobserver variability.

Descriptive statistics was used for qualitative and quantitative evaluation of agreement between SSFP and GRE-EPI respectively and MPS.

For visual assessment, on a patient level, data was first dichotomized (normal ischemic/scar on CMR and reversible - irreversible on MPS), then crosstabulated and Kappa was calculated for agreement between CMR and MPS [139].

The contrast wash-in slope on stress CMR and MPS stress score was found to be skewed (Kolmogrov-Smirnov and Shapiro-Wilk) and was normalized to peak before calculation. For each segment the wash-in slope in stress CMR and the stress score from MPS was compared using (Analysis Of Variance) ANOVA. 
Sensitivity and specificity was calculated for the two sequences (SSFP and GREEPI) with MPS as reference.

\section{Study III}

Mean score and SD were calculated for each item. Frequencies were used to describe missing data, score distribution, ceiling and floor effects.

Homogeneity was evaluated with item-total correlation adjusted for overlap. For factor structure, an exploratory factor analysis using unweighted least square was performed and confirmed with Horn's parallel analysis. A hot-deck multiple imputation was conducted to replace missing data. Internal consistency was evaluated with Cronbach's alpha. Spearman's correlation was used for calculation of criterion validity. For evaluation of known-group validity unpaired t-test was used. Test-retest between day one and two was evaluated with unweighted Kappa coefficient. Correlation between the total instrument and the two factors between day one and two was evaluated with intraclass correlation and Lin's concordance correlation coefficient.

\section{Study IV}

Pre- and post- examination data was evaluated with Wilcoxon signed-rank test. Spearman's rank correlation coefficient $\left(r_{s}\right)$ was used for correlation between questionnaires. Analysis of covariance was used to adjust for age in the comparison of anxiety between the two groups CMR and MPS and for adjustment of gender between the groups CMR-standard and CMR-video. Significance was evaluated with the Tukey test. The calculation of sample size was based on the prevalence of anxiety in patients undergoing MRI examinations in previous research [110]. Based on an expected effect size of 40\%, an alpha set at 0.05 and a power of 0.80 , a sample size of 50 participants in each study group was required.

Significance was set to $\mathrm{p}<0.05$.

All data in the thesis was analysed with

- SPSS 13.0 (SPSS Inc. Chicago, IL, USA).

- Statistica version 10 (Statsoft Inc. Tulsa, OK, USA).

- MedCalc (MedCalc Software, Mariakerke, Belgium).

- Factor 10.3 (Rovira i Virgili University, Tarrgona, Spain). 


\section{Ethical considerations}

All studies followed the Declaration of Helsinki [140], the principles of Good Clinical Practice [141] and the four principles regarding autonomy, beneficence, non-maleficence and justice [142]. The Medical Research Ethics committee at Linköping University (paper I) and the Regional Ethical Review Board in Linköping (paper II, III and IV) Sweden (registration no. 05-04, M 169-07 and 2012/279-31) approved the studies.

\section{Autonomy}

In order to respect their autonomy, all participants were given written and oral information about the study procedure and gave informed consent in accordance with Swedish law [143]. They were informed that their participation was voluntary and that they could withdraw from the study at any time without negative effects on their contact with the healthcare provider. Patients who chose not to participate were respected without asking for explanations [142].

All participants were patients and some of them had met the project leaders in their role as health care professionals. Since patients are in a dependent position, they may feel forced to participate. To avoid unintended coercion, it is of utmost importance to be perceptive and show respect for expressed wishes not to participate [142, 144, 145].

\section{Beneficence, non-maleficence}

In scientific studies including people, potential risks for negative effects for participants need to be outweighed by the benefits the study has for the population [145]. Negative effects also have to be minimized and the participants have to be offered the best treatment available. All participants were given contact phone numbers that could be used at any time.

For patients in study I and II a potential risk of incidental findings had to be adressed. In such a case a clinical report was sent to the treating physician and the patients could thereby receive early treatment. For LGE imaging and perfusion studies Gd-contrast was injected. The contrast media is known to increase the risk for nephrogenic systemic fibrosis (NSF) in patients with renal failure. To avoid this potentially severe complication, renal failure was a contraindication for participation in the study. There was also a possibility that participants could react with anxiety in the scanner. In such a situation, the patient was offered light sedation with bensodiazepines or they could choose to withdraw from the study.

For participants in study III and IV there was a risk for emotional reactions, e.g. patients who had not considered the examination to be problematic could react with a feeling of anxiousness, just because they answered questionnaires about anxiety. 


\section{Justice}

During the inclusion period all patients who fulfilled the inclusion criteria were asked to participate. When contrast media was used patients with $\mathrm{GRF} \leq 30$ were excluded due to the risk for adverse side effects [40, 41].

We do not consider that participation in any of the studies could have caused any serious negative consequences for the subjects included. Rather they received more investigations, information, attention and assessment. 


\section{RESULT}

\section{In patients with ongoing atrial fibrillation, a SS-SSFP sequence showed better image quality than IR-FGRE (I)}

\section{Image quality}

Twenty patients with atrial fibrillation and a previous myocardial infarction were investigated with the two sequences. Motion artefacts due to arrhythmia were shown to strongly and negatively affect image quality. Even though single shot images have lower spatial resolution, the SS-SSFP sequence displayed significantly better quality than the standard segmented IR-FGRE sequence in all four aspects evaluated: the delineation of non-infarcted and infarcted myocardium, the presence of motion and other artefacts and an overall evaluation of image quality of the left ventricle.

The scores (higher score indicates higher image quality) were as follows $(\mathrm{m} \pm \mathrm{SD})$ : Non-infarcted myocardium delineation was for IR-FGRE (3.6 \pm 0.7$)$ and for SSSSFP (3.9 $\pm 0.4, \mathrm{p}=0.37)$. Infarcted myocardium delineation was for IR-FGRE (2.7 \pm 0.8$)$ and for SS-SSFP (3.2 $\pm 0.6, \mathrm{p}=0.014)$ Presence of artefacts was for IRFGRE (4.0 \pm 0.8$)$ and for SS-SSFP $(4.5 \pm 0.4, \mathrm{p}=0.021)$. An overall evaluation of the left ventricle was for IR-FGRE (3.3 \pm 0.7$)$ and SS-SSFP $(3.8 \pm 0.4 \mathrm{p}=0.003)$

\section{Artefacts}

Artefacts were more frequent in cine-CMR (3.5 \pm 0.5$)$ than in both LGE-sequences (IR-FGRE 4.0 \pm 0.8 and SS-SSFP 4.5 \pm 0.4 ). Overall image quality in cine was $3.8 \pm 0.5$, in IF-FGRE $3.3 \pm 0.7$, and in SS-SSFP $3.8 \pm 0.4$. In cine images artefacts were more often seen in the basal than in the mid and apical segments of the left ventricle.

Agreement between the two observers was for IR-FGRE kappa 0.41-0.60 for three of the four aspects, which is considered "fair agreement". For the SS-SSFP sequence, kappa statistics showed generally lower agreement. 


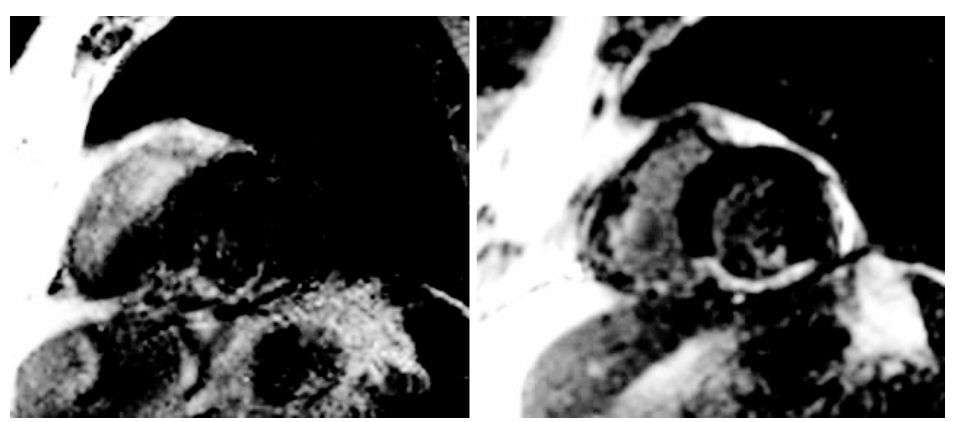

Figure 5. Patient with myocardial infarction and atrial fibrillation. IR-FGRE sequence to the left and SS-SSFP to the right.

\section{Volumes}

When values were averaged between the two observers, myocardial volume was $7 \%$ higher using SS-SSFP (170.7 ml) than IR-FGRE ( $159.2 \mathrm{ml}, \mathrm{r}=0.93, \mathrm{p}<0.001)$. Scar volume was for IR-FGRE (20.4 ml) and for SS-SSFP $(19.3 \mathrm{ml}, \mathrm{r}=0.84$, $\mathrm{p}<0.599)$. The extent of scar was for IR-FGRE (12.4\%) and for SS-SSFP (11.0\%, $\mathrm{r}=0.80, \mathrm{p}<0.229$ ).

The methodological error (Smethod according to Dahlberg) displayed no difference between the two methods regarding myocardial volume (error for IRFGRE was $36.1 \mathrm{ml}$, and for SS-SSFP $31.3 \mathrm{ml}, \mathrm{p}=0.730$ ). The error for infarct volume was for IR-FGRE $7.4 \mathrm{ml}$ and for SS-SSFP $7.8 \mathrm{ml}, \mathrm{p}=0.422$. Infarct extent had an error for IR-FGRE of 3.4\% and for SS-SSFP 3.1\%, p=0.642. End diastolic volume had a larger error with SS-SSFP, $24.5 \mathrm{ml}$ than for IR-FGRE $12.5 \mathrm{ml}$, $\mathrm{p}=0.003$.

The correlations of wall motion score index (WMSI) on infarct volume were not different between the two sequences, and the regression coefficient, (slopes) were almost identical (WMSI $=1.27+0.02 x I R-F G R E \inf (\%) ; r=0.52 ; p=0.02$ and $\mathrm{WMSI}=1.25+0.024 \times$ SS-SSFP $\inf (\%) ; \mathrm{r}=0.54 ; \mathrm{p}=0.01$. Slope difference $\mathrm{p}>0.09$ ).

\section{SI, SNR and CNR}

SI was higher in the normal myocardium, infarcted myocardium and in the blood pool using SSFP (11.0 $\pm 3.0,66.9 \pm 32.6$ and 42.6 \pm 17.0 ), compared with IR-FGRE (8.5 $\pm 4.2,44.0 \pm 17.2$ and $30.8 \pm 11.9, p=0.028,<0.001$ and $<0.001)$. However, SNR was higher in infarcted myocardium and in the blood pool for IR-FGRE (32.4 \pm 17.1 and 22.6 \pm 10.9$)$, compared with SS-SSFP (26.1 \pm 13.7 and 16.6 \pm 7.3$)$ $\mathrm{p}=0.048$ and 0.018 ). SNR in normal myocardium and CNR in infarcted myocardium and in the blood pool displayed no significant difference between the two sequences.

The time required to acquire long and short axis images of the heart was for the IR-FGRE sequence 8.8 $\pm 2.0 \mathrm{~min}$ and for SS-SSFP $4.4 \pm 1.6 \mathrm{~min}$. 


\section{For visual and quantitative evaluation of CMR stress first-pass perfusion, a GRE-EPI sequence demonstrated higher agreement with MPS than a SSFP sequence (II)}

\section{Scar and volumes}

In each group examined with either the SSFP $(n=30)$ or the GRE-EPI $(n=30)$ sequence, 10 of the patients had myocardial scar. For SSFP the scar size of the left myocardial volume was $(7.40 \% \pm 9.03)$ and for GRE-EPI $(7.10 \% \pm 5.51, p=0.92)$. All patients had an increase in heart rate exceeding 10 beats/min after

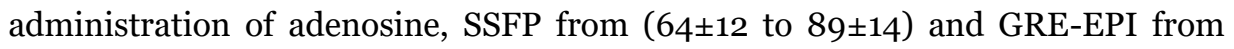
$(63 \pm 10$ to $83 \pm 16)$, indicating an acceptable pharmacological effect of adenosine.

Left ventricular end diastolic volume (LVEDV) and left ventricle ejection fraction (LVEF) evaluated with cine-CMR were for patients examined with SSFP $(145 \pm 34$

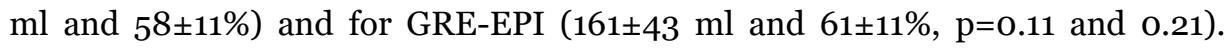
Using MPS, LVEDV and LVEF were for patients examined with SSFP (107 $\pm 43 \mathrm{ml}$ and $54 \pm 11 \%)$ and with GRE-EPI (115 $\pm 51 \mathrm{ml}$ and $56 \pm 11 \%, \mathrm{p}=0.49$ and 0.37$)$. The data suggests no difference between the two patient samples.

\section{SI, SNR and CNR}

SSFP is associated with high SI, SNR and CNR [50, 51], which was also displayed in the present study. SI, SNR and CNR were significantly higher for SSFP than for EPI-GRE in both normal and infarcted myocardium.

For normal segments at peak gadolinium, SI was for SSFP and GRE-EPI $67.72 \pm 6.40$ and $39.43 \pm 16.86(\mathrm{p}=0.007)$. SNR for normal segments was $35.63 \pm 11.80$ and $17.98 \pm 8.31(p=0.017)$, and CNR for normal segments was $28.79 \pm 10.43$ and $13.06 \pm 7.61(\mathrm{p}=0.018)$.

For definite ischemic segments (rated 3 and 4), SI for SSFP and GRE-EPI was $62.10 \pm 18.35$ and $34.72 \pm 18.81 \quad(p=0.030)$. SNR for ischemic segments was $32.31 \pm 13.31$ and $15.71 \pm 7.87(\mathrm{p}=0.030)$, and CNR for ischemic segments was for both sequences $25.18 \pm 12.48$ and $10.41 \pm 7.66(\mathrm{p}=0.039)$.

SI, SNR and CNR showed statistically significant differences between the two sequences on a per patient level, but there was no difference between normal and ischemic segments.

\section{Visual assessment}

MPS showed signs of coronary artery disease, either scar or ischemia, in 20 patients. Reversible ischemia was found in 13 of these patients. Corresponding numbers for the two CMR sequences were 29 and 22. With MPS as reference, the sensitivity for detection of pathology was for SSFP and GE-EPI $78 \%$ and $91 \%$. 
Specificity was $58 \%$ and $84 \%$. The kappa value for the agreement between MPS and SSFP was low (0.29), and good between MPS and GRE-EPI (0.72) [139] (Table 5).

Table 5. Cross tabulation of the visual assessment of CMR and MPS. MPS: normal or reversible/irreversible reduction of perfusion. CMR: normal, ischemia or scar

\begin{tabular}{lcccc}
\hline & CMR & & MPS & \\
\hline SSFP (\%) & & normal & reversible/irreversible & kappa $^{\text {a }}$ \\
& ischemic/scar & $9(56 \%)$ & $2(14 \%)$ & \\
GRE-EPI (\%) & normal & $16(94 \%)$ & $7(44 \%)$ & 0.286 \\
& ischemic/scar & $3(9 \%)$ & $1(6 \%)$ & \\
Total (\%) & normal & $28(90 \%)$ & $3(10 \%)$ & 0.724 \\
& ischemic/scar & $12(41 \%)$ & $17(59 \%)$ & 0.494 \\
\hline \hline
\end{tabular}

$\overline{\mathrm{CMR}}=$ Cardiac Magnetic Resonance Imaging, MPS $=$ Myocardial Perfusion SPECT. ${ }^{a}=0$-0.2: poor, >0.2-0.4: fair, >0.4-0.6: moderate, $>0.6-0.8$ : substantial, $>0.8$ almost preferable agreement. $\mathrm{P}=0.07$, Fisher's exact test two-sided.

For agreement between two observers intraclass correlation for the GRE-EPI sequence was 0.86, CI 95\% (o.80-0.90). For SSFP it was 0.53, 95\% (0.36-0.66). 


\section{Quantitative segmental CMR and MPS}

The slope of contrast wash-in during stress CMR was compared with MPS stress scores. For all three levels (basal, mid and apical), segments with a high stress score on MPS had lower rise in the CMR slope than MPS with low stress score. The correlation between CMR perfusion stress slope for all segments versus MPS score (four points based on MPS classification) for 18 segments was for SSFP $(\mathrm{r}=0.64=$ and for GRE-EPI $\mathrm{r}=0.96)$ (Figure 6$)$.
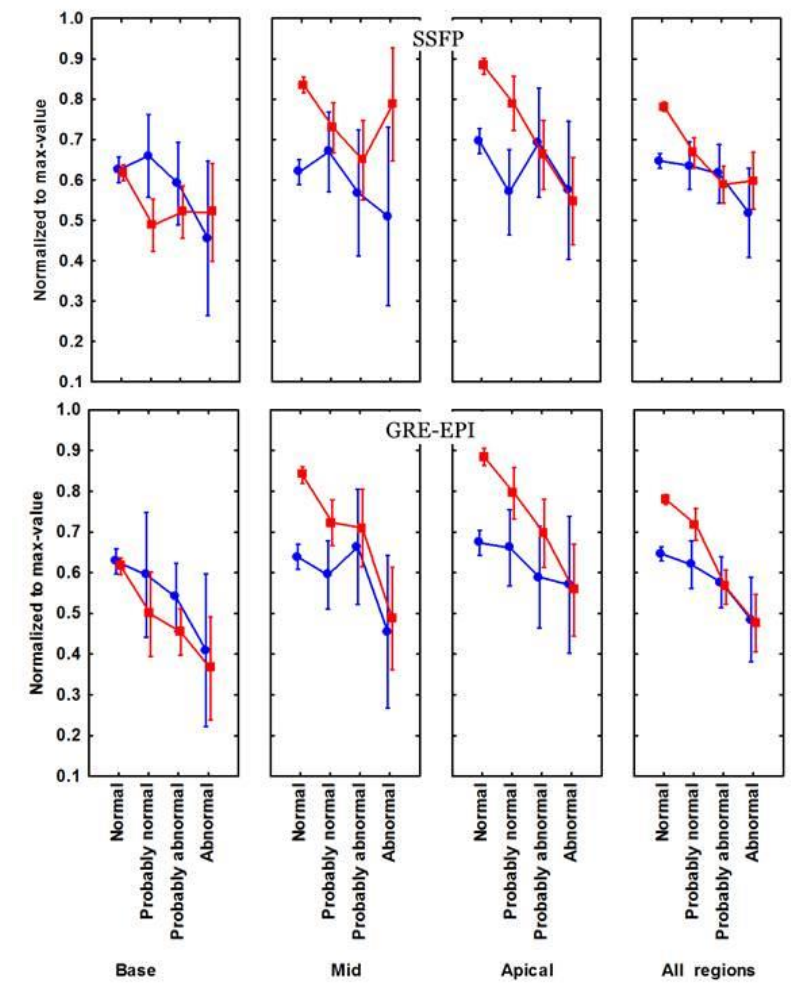

Figure 6. MPS score (red lines) and CMR slope (blue lines) during vasodilatation. SSFP (upper panel) and GRE-EPI (lower panel). Three segment levels, base, mid, apical and aggregated results to the right. Values are normalized to maximum in each individual to allow for comparison. Normal, ischemic and scar segments are all included. 


\section{Development of the Magnetic Resonance Imaging Anxiety Questionnaire MRI-AQ (Paper III)}

The questionnaire Magnetic Resonance Imaging-Anxiety (MRI-AQ, Appendix I and II) was developed and validated as part of this thesis. Eight hundred and eighy-one patients were invited to participate, of whom 247 accepted (response rate 28\%). The evaluation showed satisfactory psychometric properties of the test.

\section{Item statistics}

Evaluation of CVI resulted in the exclusion of one item, "I felt nauseous", due to a low I-CVI (0.71). After exclusion of this item, the S-CVI was 0.99 and regarded as "very good" [133].

All items were answered by $87 \%$ of the participants. Missing data for each item was equally distributed across the instrument and varied between 0-5 (0.0-2.0\%) and no items were regarded as difficult to understand. The items showed floor effects but no ceiling effects. Item-total correlation was between (0.44-0.78) except for the three questions where it was between $(-0.11-0.22)$. Alpha "if deleted" ranged between (0.86-0.89).

\section{Factor structure}

An exploratory factor analysis supported by the parallel analysis resulted in an instrument consisting of two factors explaining $52.6 \%$ of the total variance. Three of the items with low item-total correlation demonstrated communality values < 0.2 and /or factor loading < 0.4 . When those items were excluded the factor analysis explained $59.5 \%$ of the total variance. No item demonstrated multiple loadings in the rotated factor solution. This resulted in an instrument with 15 items divided into two factors, one consisting of 12 items concerning Anxiety and one with three items concerning Relaxation (Table 6).

\section{Internal consistency}

Internal consistency for MRI-AQ total scale was good $(\alpha=0.90)$ for symptoms of anxiety $(\alpha=0.90)$ and for symptoms of relaxation $(\alpha=0.89)$.

\section{Criterion related and known-group validity}

The total scale MRI-AQ as well as the factors Anxiety and Relaxation correlated higher with instruments measuring anxiety (HAD-A) than depression (HAD-D). The strongest correlation was seen between MRI-AQ and the patients' own ratings of their worry.

Known-group validity showed that patients examining the heart scored significantly higher than patients examining the spine. 
Table 6. Basis for the two-factor solution with eigenvalue $>1.0$ of the Magnetic Resonance Imaging -Anxiety Questionnaire. Factor loadings for each item. Communality calculated on unrotated factor analyses.

\begin{tabular}{|c|c|c|c|c|}
\hline \multicolumn{2}{|c|}{ Item } & $\begin{array}{l}\text { Anxiety } \\
\text { symptoms }\end{array}$ & $\begin{array}{l}\text { Relaxation } \\
\text { symptoms }\end{array}$ & $\begin{array}{l}\text { Communality } \\
\text { values }\end{array}$ \\
\hline \multicolumn{5}{|c|}{ Factor I / Anxiety symptoms } \\
\hline 1 & I felt that I controlled the situation & 0.55 & 0.34 & 0.42 \\
\hline 2 & I had palpitations & 0.60 & 0.21 & 0.40 \\
\hline 3 & I found it hard to breathe & 0.63 & 0.18 & 0.43 \\
\hline 4 & I was afraid & 0.86 & 0.27 & 0.81 \\
\hline 5 & I wanted to come out & 0.74 & 0.25 & 0.61 \\
\hline 6 & I panicked & 0.75 & 0.24 & 0.62 \\
\hline 9 & I worried in advance & 0.48 & 0.18 & 0.26 \\
\hline 11 & $\begin{array}{l}\text { I had to force myself to manage the } \\
\text { situation }\end{array}$ & 0.78 & 0.29 & 0.69 \\
\hline 12 & $\begin{array}{l}\text { Self-control was required when going } \\
\text { through the examination }\end{array}$ & 0.71 & 0.15 & 0.52 \\
\hline 13 & I needed support and encouragement & 0.75 & 0.18 & 0.59 \\
\hline 14 & I wished to have someone with me & 0.56 & 0.15 & 0.33 \\
\hline 15 & $\begin{array}{l}\text { I needed more detailed information } \\
\text { Factor II / Relaxation symptoms }\end{array}$ & 0.54 & 0.16 & 0.31 \\
\hline 7 & I felt relaxed & 0.21 & 0.84 & 0.76 \\
\hline 8 & I felt safe & 0.16 & 0.91 & 0.85 \\
\hline 10 & I felt calm & 0.24 & 0.74 & 0.60 \\
\hline & Eigenvalues after rotation & 7.19 & 1.74 & \\
\hline & Explained variance after rotation, \% & 47.95 & 11.58 & $\mathbf{5 9 . 5 3}{ }^{\mathrm{a}}$ \\
\hline
\end{tabular}

\section{Stability}

In test-retest, the weighted kappa coefficient demonstrated fair to good agreement ( $\mathrm{K} w=0.42-0.79)$. For the total scale MRI-AQ and for the two factors, intraclass correlation varied between (0.49-0.94) and Lin concordance between (0.48-0.94). 


\section{Video information prior to CMR examination resulted in more relaxed patients, but motion artefacts were not reduced. Patients who underwent CMR had higher levels of anxiety than those who underwent MPS (Paper IV)}

Two hundred and fourteen patients were invited and 148 answered the questionnaires before and after the examination, giving a response rate of $69 \%$.

\section{Comparisons immediately after the examinations}

According to MRI-AQ, the study group that watched a video explaining the examination procedure prior to CMR scored significantly lower (better) than the control group in the factor Relaxation $(p=0.039)$ (Table 7$)$. This difference was still present when adjusted for gender (Table 8). No difference was found between the two CMR groups in the total scale or in the factor Anxiety.

Table 7. Comparison between the group scores on MRI-AQ total scale, the factors Anxiety and Relaxation.

\begin{tabular}{lccccc}
\hline & $\begin{array}{c}\text { CMR- } \\
\text { standard } \\
\mathrm{n}=48\end{array}$ & $\begin{array}{c}\text { CMR- } \\
\text { video } \\
\mathrm{n}=49\end{array}$ & $\begin{array}{c}\text { p-value b) } \\
\text { CMR-s } \\
\text { /CMR-v }\end{array}$ & $\begin{array}{l}\text { MPS } \\
\mathrm{n}=51\end{array}$ & $\begin{array}{c}\text { p-value } \\
\text { CMR/MPS }\end{array}$ \\
\hline $\begin{array}{l}\text { MRI-AQ a) } \\
\begin{array}{l}\text { MRI-AQ } \\
\text { factor of Anxiety a) }\end{array}\end{array}$ & $22(17-32)$ & $22(18-26)$ & 0.412 & $18(15-21)$ & $<0.001$ \\
$\begin{array}{l}\text { MRI-AQ } \\
\text { factor of Relaxation a) }\end{array}$ & $6(3-5-8.5)$ & $5(3-6)$ & 0.039 & $3(3-6)$ & 0.029 \\
\hline \hline
\end{tabular}

a) med (IQR) b) Mann Whitney U-test. CMR=Cardiovascular Magnetic Resonance imaging, MPS $=$ Myocardial Perfusion SPECT

When the two examinations MPS and CMR-standard were compared, patients who underwent MPS scored significantly lower on the MRI-AQ total scale ( $\mathrm{p}<0.001)$, and the factors Anxiety $(\mathrm{p}<0.001)$ and Relaxation $(\mathrm{p}=0.029)$ (Table 7). This difference was also present when adjusted for age (Table 8). 
Table 8. Comparison between MRI-AQ total scale and the two factors regarding patient experience of CMR-s ( $\mathrm{m}=49.3$ years) and MPS ( $\mathrm{m}=64.5$ years $)$, with and without adjustment for age. Comparison between CMR-standard (female 26/male 22) and CMR-video (female 14/male 35), with and without adjustment for gender.

\begin{tabular}{|c|c|c|c|c|}
\hline 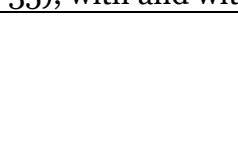 & $\begin{array}{c}\text { p-value }{ }^{\text {a) }} \\
\text { CMR-s/MPS } \\
\text { n=48/51 }\end{array}$ & $\begin{array}{c}\text { p-value } \mathrm{b}) \\
\text { CMR-s/MPS } \\
\mathrm{n}=48 / 51 \\
\text { Adjusted for age }\end{array}$ & $\begin{array}{c}\text { p-value a) } \\
\text { CMR-s/CMR-v } \\
\text { n=48/49 }\end{array}$ & $\begin{array}{c}\text { p-value } \mathrm{b}) \\
\text { CMR-s/CMR-v } \\
\mathrm{n}=48 / 49 \\
\text { Adjusted for gender }\end{array}$ \\
\hline MRI-AQ & $<0.001$ & $<0.001$ & 0.158 & 0.153 \\
\hline $\begin{array}{l}\text { MRI-AQ } \\
\text { Factor of Anxiety }\end{array}$ & $<0.001$ & $<0.001$ & 0.384 & 0.376 \\
\hline $\begin{array}{l}\text { MRI-AQ } \\
\text { Factor of } \\
\text { Relaxation }\end{array}$ & 0.009 & 0.016 & 0.012 & 0.020 \\
\hline
\end{tabular}

When the total sample was compared, women scored significantly higher than men on the MRI-AQ total scale $(\mathrm{p}=0.024)$ and the factor Anxiety $(\mathrm{p}=0.012)$. For the factor Relaxation, there was no difference. The same was found between those who were psychologically unhealthy, who scored higher than those who were not total scale $(\mathrm{p}=0.025)$ and factor Anxiety $(\mathrm{p}=0.005)]$, but not on the factor Relaxation.

When the CMR patients in both the CMR-standard and the CMR-video groups were divided into two groups based on age ( $\leq 49$ years and $>49$ years, which was the median age), young participants scored significantly higher than older participants in HAD-A $(\mathrm{p}=0.009)$, STAI-S $(\mathrm{p}=0.001)$ measured before the examination and in MRI-AQ responses for Anxiety $(p=0.034)$, measured immediately after the examination.

All study groups had lower levels of situational anxiety (STAI-S) immediately after the examination than before, CMR-video $(\mathrm{p}<0.001)$, CMR-standard ( $\mathrm{p}=0.001)$, and MPS $(\mathrm{p}=\mathrm{o.001})$.

Correlations between MRI-AQ total scale, the factors Anxiety and Relaxation and the other scales varied between $r^{s}=0.207$ and $r^{s}$ 0.684. The highest correlation was found between MRI-AQ anxiety and the patients' ratings of their worry. CAQ Avoidance and HAD D displayed no or week correlations.

\section{Follow-up one week after the imaging procedure}

Heart focused anxiety determined by the CAQ score showed no significant difference before and one week after the examination for CMR-standard $(\mathrm{p}=\mathrm{0.838})$ or MPS $(\mathrm{p}=0.388)$. Statements dealing with fear in situations related to MRI examinations (MRI-FSS) showed no difference after one week, compared to before the examination. In the three study groups, the results of the total scale 
MRI-AQ, and the factors Anxiety and Relaxation showed no significant change immediately after and one week after the examination.

\section{Comparison of image quality}

The presence of motion artefact as an indirect expression of the degree of patient anxiety and cooperation was similarly detected in the CMR-groups, both the intervention (20 \%) and the control group (20 \%, p=1.00o). The agreement between the observers was in the interval $71-74 \%$. 


\section{DISCUSSION}

\section{Aspects on participants and methods}

\section{Study I}

Patients with atrial fibrillation and verified MI have as a group a reduced general state of health. They are often elderly and disabled. For participation in study I the participants had to be healthy enough to travel to a hospital for the CMR examination. Twenty patients were included in the study. A larger sample was difficult to achieve considering the voluntary nature of research, the frailty of old patients and the recruitment base of 220000 inhabitants in the catchment area. Furthermore, a paired analysis was possible since each patient was examined with both sequences.

\section{Study II}

The time for inclusion seems long, but access to the MRI scanner was limited. Randomization to the two sequences was not possible since only one sequence (SSFP) was available when the study started. Neither was a cross-over study where all patients were examined with both sequences feasible, since that would have required two runs of adenosine stress. There are different recommendations about the amount of contrast injected during perfusion imaging. Wolff et. al. [146] showed that a dose of $0.05 \mathrm{mmol} / \mathrm{kg}$ is optimal. In study II, $8 \mathrm{ml}$ was used for all patients. Eight $\mathrm{ml}$ contrast corresponds to $0.05 \mathrm{mmol} / \mathrm{kg}$ in a patient weighing $80 \mathrm{~kg}$. Mean weight for the participants was $78 \mathrm{~kg}$.

The patients studied were not scheduled for ICA, since non-invasive studies are used as gate-keepers for angiography in our hospital. Positron Emission Tomography (PET) could have replaced MPS, but it was not available.

\section{Study III}

In this study, 247 of 881 patients answered the questionnaire, giving a response rate of $28 \%$, which gives a reasonable sample of the population of prospective MRI patients and their attitudes. Validation is an ongoing process and a different selection of respondents could possibly have produced a different result [134]. The sample size recommended for a factor analysis can be calculated as a ratio between participants and items of 10-15 per item [147]. In absolute numbers, a sample size between 100 and 1000 is recommended, with 1000 participants being considered as excellent [148]. In study III, the MRI-AQ had 15 items and 247 participating patients, which we consider sufficient.

Two groups of patients were asked to participate, those examining the heart or those examining the spine. MRI spine was chosen for comparison since it is one of the most common MRI examinations and facilitates patient recruitment. MRI 
of the spine is also considered to be less demanding for the patient compared with heart examinations, which enables evaluation of known-group validity. The number of participants who examined the spine was greater than those who examined the heart, reflecting the frequency of referral in clinical settings.

In this study a parametric statistical method was used, despite the data being on an ordinal level. Factor analysis and item-total correlation need parametric evaluations, which were used throughout the statistical calculations. With one exception, correlation between the instruments was, after recommendation from reviewers, evaluated with Spearman correlation. This did not change the result.

\section{Study IV}

The participants who underwent CMR in study IV were allocated in such a way that every other participant was given standard information. The others watched an information video in addition to standard written information. This procedure resulted in a significant difference in the ratio of women to men between the study groups. The CMR-standard had a higher proportion of women compared with both the CMR-video and the MPS groups. Since women scored significantly higher than men in the MRI-AQ total scale and the factor Anxiety, this could be a bias. However, the factor Relaxation scored differently between the CMR groups and the result in this factor remained after adjustment for gender. The patients referred for MPS were significantly older than the CMR groups, but after adjustment for age the scoring difference remained.

The Magnetic Resonance Imaging-Anxiety Questionnaire was validated on patients who underwent MRI and developed with the purpose to evaluate patient experience during MRI examinations and not during MPS. The two factors Anxiety and Relaxation relate to the anxiety that can be felt due to the restricted environment in a MRI scanner and patients' ability to relax. The gamma camera also has a restricted environment, which justifies the use of MRI-AQ for comparing these methods. MRI-AQ also showed that it can be used to detect differences between the two modalities.

The presence of motion artefacts depends on patient cooperation in addition to the fact that the heart is constantly beating. Another important factor that cannot be improved by an information intervention is the difficulty patients have holding their breath. Arrhythmia can be mistaken for motion artefacts. The radiographer performing the examination has a very important role coaching the patients to do their very best and continue the examination until high quality images have been obtained. Scanner performance affects image quality, e.g., a low slew rate of the gradients and insufficient flow compensation can cause image blurring. Artefacts related to arrhythmia and scanner performance can also hide true motion artefacts.

It has been suggested that the levels of cortisol and prolactin measured during scanning may disclose patient anxiety [98]. In the present study we decided not 
to use such parameters but only evaluate the patient's own experience and thereby rely on questionnaire data.

\section{General discussion}

\section{Image quality}

CMR examinations with high image quality are difficult to achieve, not only for the patient but also for the staff working with MRI, physicians, as well as radiographers. To succeed, both categories have to be well trained [149]. The path to a successful examination with good quality may differ between patients. The condition of the patient has to be considered. The presence of arrhythmia, difficulties in breath holding or problems in immobilisation need to be addressed. If the patient is in sinus rhythm and can hold breath the problem is reduced considerably [67]. This has to be considered in the planning phase of every examination. Most artefacts are related to motion [150] and degrade image quality, but can be recognized and corrected during the ongoing examination [66].

The size of a scar detected by LGE-images is known to correlate with clinical determinants of infarct size [63]. Image quality has to be good enough to allow the identification of a scar and determine the extent as well. Furthermore, the determination of reversible ischemia from perfusion [64] and the ability to predict long-term outcome after ST-elevation myocardial infarction [151] using LGE are important aspects of CMR. Single shot SSFP has earlier been found to have sufficient image quality in patients without arrhythmia [152]. In study (I) we showed that a single shot sequence enables the examination of arrhythmic patients that earlier were almost impossible to study with CMR. The advantage of the elimination of motion artefacts overshadows the loss of resolution. The high correlation between myocardial volumes, infarct volume and infarct extent between the two sequences enables SS-SSFP to be used as a satisfactory alternative for the evaluation of scar size. The single shot sequence shortens the acquisition and the patients can breathe normally during the entire LGE acquisition with no need for a pause. A short examination is also useful in patients with difficulties to hold their breath and in patients who for other reasons, for example pain, have problems being immobilized. Anxious patients might only be able to participate in a short examination.

For non-invasive evaluation of stable ischemia, MPS is the standard method [153], at the price of using radiation. Even if scintigraphy is the clinical standard of care, there are situations where the MPS study may be negative, despite the presence of significant coronary stenosis, e.g., when there is stenosis in all three perfusion territories, causing "balanced ischemia" [154]. CMR first-pass perfusion uses no radiation and has high sensitivity and specificity for detection of ischemia. The disadvantage has been partial coverage of the heart. Still, 
previous studies comparing the diagnostic value of MPS and CMR [56, 57] have shown CMR to perform well. CMR may display perfusion, wall motion and LGE in one appointment [54]. The diagnostic accuracy from CMR first-pass perfusion increases when the information from LGE images is added to the evaluation. Several sequences can be used for perfusion studies, for example, FLASH, SSFP and GRE-EPI [57, 73, 146]. Fenchel et al. [73] found a SSFP sequence superior to FLASH. Though artefacts were more common, the SSFP sequence correlated higher with MPS than the FLASH did. In study (II), SSFP and GRE-EPI sequences were compared, with MPS as reference. When a qualitative, visual comparison of the ability to detect ischemia was performed and contrast enhancement on LGE was considered pathologic, GRE-EPI showed better agreement with MPS than SSFP, even though the SSFP sequence had significantly higher SI, SNR and CNR. One reason why GRE-EPI was found to be superior is the dark-rim artefact. This artefact is seen as a dark subendocardial band, which can be mistaken for a true perfusion defect [27, 69-71]. This artefact is more often seen in SSFP images than in GRE-EPI $[69,70]$.

The result in both study I and II shows that avoiding artefacts is of primary concern in order to maintain high image quality. Naturally, SI, SNR and CNR have to be reasonable. It is clear that artefacts greatly decrease image quality and diagnostic accuracy.

When the presence of motion artefacts in study IV was assessed, the addition of video information showed no difference between groups. This is in contrast to a previous study [68] where the improved information increased image quality. In study IV the result could have been affected by the performance of the scanners, and the result could also have been different without the experienced staff that collected new images to replace those with a low image quality.

\section{Measurement accuracy}

The reproducibility of qualitative evaluation of first-pass perfusion is affected by the experience of readers [155] and a quantitative method is needed. However, quantitative analysis has some problems, such as motion compensation and a correct segmentation of the myocardium [155]. Inclusion of the high signal from the blood pool may increase signal intensity during up slope, which could hide perfusion defects. The amount of contrast media used influences the result [158], as well as the sequence being used [155]. Several semi-quantitative and quantitative methods can be used. When the slope during contrast injection was measured, the GRE-EPI sequence showed better agreement with MPS than did SSFP. In qualitative analysis, the dark rim artefact can be problematic and in quantitative analysis it can cause a decrease in SI during upslope [69], which prevents the software from discriminating between true perfusion defect and artefact. Even if the correlation between quantitative evaluation of CMR perfusion and MPS was promising, the semi-quantitative tool was too timeconsuming to use and thus not useful in daily clinical practice. 


\section{Development of MRI-AQ}

For the evaluation of patient benefit from extended information prior to CMR, a new measurement was needed. The STAI-S is the questionnaire frequently used in previous research $[68,98,110,116,156]$. Even if the "state" scale has been used for measuring ongoing anxiety at a particular moment, the items do not refer to the situation in a MRI scanner, but measure anxiety in daily life, which may be completely different. This can be illustrated by patients who do not suffer from anxiety in daily life but still experience difficulties in the scanner. The low correlation we found between MRI-AQ and STAI-S, as well as between HAD A and MRI-AQ supports this assumption. If the correlation had been higher, the development of a new questionnaire had not been necessary [135]. The items in the new questionnaire relate to the situation in the scanner and to the physical responses to anxiety. All items were selected from a study where patients were interviewed about their feelings during the examination [94], which ensures that the items in the questionnaire cover the expected domain, high content validity. Content validity is perhaps the most important measurement during development and validation of a new questionnaire [157]. Initially, the instrument consisted of 22 items. During a step-wise evaluation by independent experts working in the field, a number of items were excluded. The fact that the expressions of the patients participating in the interviews were accounted for is a particular strength of this selection process. The last items were excluded due to poor psychometric properties, leaving a final number of 15 .

MRI-AQ is aimed at measuring and differentiating between patient feelings during MRI. Known-group validity is thereby an important part of the validation [157]. When validated on patients, the instrument was able to differentiate between patients who performed MRI-examinations of either the spine or the heart. Patients subjected to cardiac MRI scored significantly higher than those who underwent a study of the spine. This is plausible since MRI of the spine is a short examination (about $15 \mathrm{~min}$ ), and the patients can breathe freely and only need to be immobilized for a short time in the scanner. In contrast, MRI of the heart requires the patients to be cooperative holding breath, and the examination frequently lasts for almost an hour. The long duration is often disliked by patients [95].

The validation process resulted in an instrument with good psychometric properties and the possibility to distinguish between patients examining the heart and the spine. MRI-AQ measures patients' experience of anxiety during MRI examination, not anxiety in ordinary life. Therefore, it can be used to evaluate interventions, when new methods are introduced and whenever it is of value to find out of patient reactions in connection with MRI

\section{Extended video information}

It is imperative to be able to execute a high quality imaging procedure with respect for patient needs and without unnecessary demands on the part of the 
patient $[117,158]$. Pertinent information may increase patient satisfaction. Video information before CMR helped the patients relax during imaging but did not affect their feelings of anxiety. Anxiety expresses a state of helplessness, a sense of uncontrollability focusing on a future threat or danger [100], whether focused on the heart, on the experience during CMR, or in daily life. Still, being more relaxed helped patients handle their anxiety.

Information is crucial and must be easy to understand while still giving the patients the knowledge they need. Patients want to know about the shape of the scanner with its spatial constraint, if the examination is noisy and the expected duration of the examination [95], which is long compared with ordinary x-ray examinations and computed tomography. Extended written or oral information prior to MRI has been evaluated in previous studies. The time spent on information has varied. Written information has been mailed with the allotted appointment time. This is easy, but the result has varied $[68,159]$. It has also been difficult for patients to imagine what the information wants to convey [158]. Oral extended information and psychological support have shown better results $[98,110,116,117]$, but the time spent giving this information has sometimes been very long [116]. Video information has the advantage of using both hearing and sight. When the patients know what the scanner looks like and expect the noise it produces, they can better comply with the instructions from the staff. They have seen and heard it before

The timing of information is important. Before the examination, patients are stressed and may have difficulties to concentrate on understanding information. It has been suggested that patients take in information better if it is received earlier [159]. A different method to distribute video information could be to provide a link to a web page with the appointment letter. The patient can view the video repeatedly if necessary. Adequate information is the basis for eliciting patient cooperation, but the need for good interaction between patient and staff during imaging is equally important $[117,158]$.

Patients with cardiac disease might feel a general anxiety due to their disease, which could negatively affect the experience of imaging procedures. However, this study showed a very low or no correlation between heart focused anxiety and patient anxiety during the examination. This can perhaps be explained by the result in a meta-analysis, including 38 studies, where the number of patients with anxiety in relation to their heart failure varied between $6.3 \%$ and $72.3 \%$ [160]. If only $6.3 \%$ of the participants felt anxious with respect to a heart failure diagnosis, the effect of information will be almost impossible to measure.

According to the MRI-AQ total scale and the two factors, MPS was easier to tolerate than CMR. MPS patients expressed less anxiety before the examination than CMR patients, possibly due to having undergone image acquisition a few days earlier in the stress part of their cardiac examination. Still, one patient who underwent MPS described the difference as "If it had been an MRI-examination anaesthesia had been required. I have panicked before". The design of the gamma 
camera is more open and the staff can be in contact with and interact with the patients during the examination.

\section{Clinical implications and future studies}

The present thesis has highlighted image quality in CMR and the anxiety that affects patients in relation to MRI. In order to provide good patient care during radiology procedures, all information given by physicians and nurses/radiographers needs to be relevant to the performance of imaging.

When performing CMR, detailed knowledge of available sequences may determine whether images of sufficient quality can be obtained or not.

In atrial fibrillation, a single shot sequence is preferable instead of a segmented. The single shot sequence is beneficial also to patients with difficulties in breath holding or for those who have other difficulties to cooperate. For evaluation of ischemia, the GRE-EPI sequence is preferable to the SSFP sequence. If the SSFP sequence is used because of additional requirements, artefacts that can be mistaken for ischemia need to be ruled out.

In general nursing as well as in nursing related to imaging procedures, we need to know the subjective experience of our patients. The MRI-AQ questionnaire can evaluate interventions to alleviate patient anxiety in connection with MRI, thereby improving future care.

Providing suitable information to patients in connection with MRI is a complex issue. Sometimes the information given can be difficult to process for the patient. Patient information can be personalized to a much larger extent than what is the case today. Conventional patient information is text-based, but these days it can be visual as well as oral and easy to repeat. Video information prior to examinations is of great value to all radiology procedures, not only CMR. Video can be provided either as a link to a webpage or as a video clip available in the waiting room. A video could be particularly well suited to people who cannot read, to patients with cognitive deficits and to those who speak foreign languages.

This study is focused on the patient experience of CMR and MPS, but we do not suggest that imaging procedures be selected on the basis of patient experience. On the contrary, we need to choose procedures that produce the best contribution to medical diagnosis, without being too difficult to endure by our patients. The experience should preferably be as positive as possible for patients. In study IV we found that video information prior the examination helped patients to relax.

Thoughts and questions regarding further research have arisen in my mind during my research process. A number of topics for further study have been identified, such as: 
- Does video information prior to MRI examinations of children and nonSwedish speakers have the potential to better prepare the patients for the examination?

- Can video information to children prior to the MRI examination decrease the use of anesthesia and sedatives?

- Can video information in the native language remove the need for an interpreter?

- If the study was to be repeated again, would the use of identical scanners uphold the findings?

- Would a wider tunnel, less noise, higher field strength and faster sequences shorten examinations, thus contributing to improve patient comfort? 


\section{CONCLUSION}

An SS-SSFP sequence recorded during free breathing displayed significantly better image quality than an IR-FGRE sequence in the evaluation of infarct size in patients with atrial fibrillation. Scar size was similar when using the two sequences. We conclude that the SS-SSFP sequence can be used in patients with arrhythmia as well as in patients with difficulties holding their breath.

For qualitative and semi-quantitative evaluation of ischemia during first-pass perfusion CMR, a GRE-EPI sequence showed a significantly higher correlation with MPS than a SSFP sequence, despite lower SI, SNR and CNR.

The development of an MRI-specific instrument for measurement of patient experience during MRI, the Magnetic Resonance Imaging- Anxiety Questionnaire -MRI-AQ, resulted in an instrument with two factors, "Anxiety" and "Relaxation", with excellent psychometric properties. It showed promising results for distinguishing between patient experience during MRI examinations of the heart and the spine. MRI-AQ can be applied for the evaluation of effects of interventions to increase well-being in the context of MRI.

Extended video information prior to CMR examinations resulted in patients with significantly lower (better) level of relaxation than in patients who received only standard text information. They were more relaxed, more calm and more safe throughout the examination.

Patients who underwent MPS with standard text information scored significantly lower (better) levels on MRI-AQ, both on the total scale and the two factors Anxiety and Relaxation, than patients who underwent CMR with standard text information.

Image quality was not affected by information given. 


\section{SAMMANFATTNING}

Ischemisk hjärtsjukdom medför att syreförsörjningen till hjärtat i vissa situationer är otillräcklig. Sjukdomen kan uttryckas som allt från icke symptomgivande arterioskleros till hjärtinfarkt och död. Det är en sjukdom som kan utvecklas redan i barndomen hos individer med ärftlig benägenhet och förvärras över tid. Sjukdomens progress beror på ett antal riskfaktorer men allt är inte känt och fortfarande finns kunskapsluckor. Nära släktingar som har ischemisk hjärtsjukdom ökar risken att insjukna i tidig ålder. Andra riskfaktorer är t.ex. rökning, högt blodtryck, förhöjda kolesterolvärden, diabetes, fetma och hög ålder, vilka samtliga påverkar sjukdomsförloppet negativt. Demografiska förändringar med ett ökat antal åldringar ökar sjukdomsprevalensen. Tidig diagnos ökar möjligheten till prevention. Sekundär prevention efter genomgångna hjärthändelser är idag självklart, men primärprevention hos riskindivider utan besvär är fortfarande omdebatterat. Flera bildgivande, ickeinvasiva, undersökningsmetoder som magnetkamera-undersökning (MR) av hjärtat (CMR) och hjärtscintigrafi (MPS) kan användas för att påvisa otillräcklig blodgenomströmning i hjärtmuskeln. Vid magnetkameraundersökning används ett starkt magnetfält och radiovågor för att avbilda kroppen. Vid hjärtscintigrafi injiceras en isotop i blodet och dess upptag registreras av en gammakamera. Fördelen med CMR är att ingen strålning används och att upplösningen i bilderna är hög.

Utbredningen av hjärtskadan efter genomgången hjärtinfarkt är betydelsefull för patientens behandling och återhämtning. Revaskularisering utförs för att lindra bröstsmärta, "kärlkramp", men också för att försöka förbättra pumpförmågan och återvinna hjärtmuskelns funktion. Vid stor hjärtinfarktskada förbättras sällan pumpförmågan även om blodtillförseln ökar. Standardmetod för att utvärdera potentialen till förbättrad funktion är CMR. Ett kontrastmedel injiceras intravenöst och det kontrastförstärkta blodets passage genom hjärtat åskådliggörs varigenom eventuell ischemi kan diagnosticeras. Efter $10 \mathrm{~min}$ tas bilder av infarktärret. För CMR undersökningar finns olika typer av bildsekvenser, vars för- och nackdelar för respektive frågeställning behöver belysas.

Hjärtscintigrafi är standardmetoden för utvärdering av ischemi. De delar av hjärtat som har nedsatt blodförsörjning har lägre upptag av isotopen än de friska delarna och har därför inte lika hög signal vid bildtagning. Undersökningen utförs under arbete och vid påverkad arbetsbild, även under vila, för att utvärdera förekomst av syrebrist i hjärtmuskeln. 
I samband med MR-undersökningen upplever patienter ofta någon form av ångest, oro eller rädsla. Till stor del beror denna oro/ångest på magnetkamerans tunnelliknande utformning, det höga ljudet under bildtagning, att undersökningen är relativt tidskrävande och att patienten är skild ifrån personalen. Känslan av oro/ångest kan förstärkas av oförmågan att kontrollera situationen. Magnetkamerorna har successivt förbättrats med kortare och bredare kameratunnel men problemet med att vissa patienter upplever undersökningen svår att tolerera kvarstår. Detaljerade studier av hur patienter upplever MPS saknas. Utökad skriftlig och muntlig information vid MRundersökning har med varierande resultat testats för att se om patienten kan bättre förberedas för att underlätta genomförandet.

Syftet med denna studie har varit att:

Utvärdera bildkvaliteten vid CMR undersökning genom val av sekvens vid undersökning av infarktutbredning hos patienter med förmaksflimmer och vid studie av hjärtmuskelns genomblödning, och eventuell inverkan av given information.

Att studera patientens upplevelse av CMR med målet att kunna förbättra patientupplevelsen och undersökningens bildkvalitet.

Standardsekvens för att bedöma hjärtinfarkters utbredning i hjärtmuskeln med MR har varit en segmenterad sekvens (i denna studie IR-FGRE) där data har samlats in under flera hjärtslag. Detta är till nackdel när patienten har arytmi som t.ex. förmaksflimmer. Då är risken stor att rörelseartefakter minskar möjligheten att diagnostiskt bedöma bilden. Nya snabbare metoder har utvecklats, där en bild samlas in under ett hjärtslag, s.k. single-shot sekvenser (i denna studie SS-SSFP). I delarbete I har dessa två sekvenser jämförts på 20 patienter med förmaksflimmer och genomgången hjärtinfarkt. Resultatet visade att single-shot sekvensen hade bättre bildkvalitet än den segmenterade och att utvärdering av infarktens utbredning överensstämde mellan de båda sekvenserna. Detta visar att det är möjligt att för patienter med förmaksflimmer eller annan typ av arytmi och för patienter som har svårt att hålla andan utföra magnetkameraundersökning av hjärtat med god bildkvalitet.

I delarbete II jämfördes två olika sekvenser för bedömning av ischemi (SSFP och GRE-EPI) med 30 patienter i varje grupp med MPS som standardmetod. GREEPI gav bäst resultat trots att SSFP sekvensen hade högre signal, signal-brus- och kontrast-brus-förhållande. Samma fördel för GRE-EPI erhölls oavsett om undersökningarna utvärderades visuellt eller med hjälp av mätning på bilden. En anledning kan vara en artefakt som är mer frekvent synlig på SSFP än på GREEPI, "the dark rim artefact". Denna syns i muskeln nära kanten mot hjärtkammaren och kan misstolkas som nedsatt genomblödning. 
För att kunna utvärdera nyttan av utökad information i samband med MR utvecklades i delarbete III ett skattningsinstrument "Magnetic Resonance Anxiety Questionnaire MRI-AQ". Instrumentet bygger på resultatet från en intervjustudie av patienter som genomgått MR-undersökning. Skattningsinstrumentet har validerats och består av två faktorer, en som mäter oro/ångest (12 påståenden) och en som mäter avslappning (tre påståenden) i samband med undersökning. MRI-AQ som testades vid MR-undersökning av rygg och hjärta hade psykometriska förutsättningar för att kunna utvärdera patientens upplevelse av MR undersökningen. I delarbete IV utvärderades videoinspelning i tillägg till standard skriftlig information jämfört med enbart standard information efter det att deltagarna slumpmässigt fördelats till olika grupper. De patienter $(n=49)$ som fick utökad information med en videoinspelning hade signifikant lättare att slappna av vid undersökningen jämfört med gruppen $(n=48)$ som enbart fick skriftlig information. Vid jämförelse av patientens upplevelse vid MPS $(n=51)$ och CMR undersökning där båda grupperna fick standardinformation, upplevde patienterna som genomgått MPS signifikant lägre oro/ångest än det som genomgick CMR. Däremot påverkade inte den utökade videoinformationen rörelseoskärpa i bilderna vid CMR undersökningarna.

Slutsatserna i avhandlingen är:

- Vid undersökning av infarktstorlek hos patienter med kroniskt förmaksflimmer ger en SS-SSFP sekvens högre bildkvalitet än IR-FGRE.

- Vid bedömning av ischemi hos patienter med regelbunden hjärtrytm överensstämmer resultatet vid CMR undersökning bättre med MPS när en GRE-EPI sekvens används jämfört med SSFP. Detta gäller både kvalitativ och semi-kvantitativ utvärdering.

- MRI-AQ bedöms som ett tillförlitligt instrument att utvärdera effekten av interventioner för att öka patienten välmående i samband med MRundersökning.

- Utökad information med video gör patienter mer avslappnade $\mathrm{i}$ undersökningssituationen.

Fortsatt forskning behövs för att utvärdera om utökad information inför MRundersökning kan vara värdefull även $\mathrm{i}$ andra patientgrupper. Frågor lämpliga att belysa kan vara om behovet av fullnarkos av barn minskar om undersökningsinformation ges som video liksom eventuell påverkan av magnetkameratunnelns diameter på patientens upplevelse av undersökningen. 


\section{ACKNOWLEDGEMENTS}

Even if I was not sure that it really would happen, an eventful journey has come to its end. There has been a lot of work that I never had been able to finish without different kinds of help and support.

I would like to express my sincere gratitude to everyone who in different ways has supported me and made it possible to complete this work.

In particular I wish to thank:

All the participating patients for your time.

Jan Engvall: main supervisor, for introducing me to research. For being my supervisor and guiding me through the work with my Bachelor, my MSc and then accepting me as a PhD student. For sharing your great knowledge and experience, for always being enthusiastic and innovative.

Elisabeth Ericsson: co-supervisor, for your interest and support throughout this work. You have been an inspiration, always friendly, encouraging and enthusiastic.

Eva Maret: co-supervisor, for sharing your experience in the field of CMR, encouraging support and advice in the research process.

Co-authors: for sharing your knowledge with me. Kristoffer Årestedt for your great statistical support when developing MRI-AQ. Lars Brudin, your way to handle data is admirable. Lene Rosendahl for sharing your knowledge and enthusiasm. Sven-Åke Stark for sharing your knowledge in SPECT.

P-G Björklund: for sharing your great knowledge throughout the years and guiding me in the truly complex world of MRI, and always answering my questions in the field.

Bo Rolander: for valuable statistical support.

Oskar Löfgren: head of the X-ray department Jönköping County Hospital. For letting me go on with my studies.

Kerstin Tellander-Pierre and Jennie Thunberg: former care unit manager and care unit manager at the X-ray department at Ryhov County 
Hospital. Always supporting me, trying to give me time even when it was difficult and we were short-staffed.

Anne Schaller: PhD-student. For going to seminars together, for discussions about research and what it is like being a PhD-student.

Anette Smedlund: Department of Radiology, Aleris Sabbatsberg Hospital, Stockholm, Johan Kihlberg Center for Medical Image Science and Visualization (CMIV), Linköping, Lars Persson Department of Clinical Physiology Ryhov County Hospital, Jönköping, Teresa Ågren Gävle Hospital, Gävle and your colleagues for friendly help and support during data collection.

My colleagues at the X-ray Department Ryhov: for your support and help during data collection. For your help with all the things that did not work out in the way I wanted them to.

All the staff at the medical library Ryhov: for always being friendly and helpful.

My friends: none mentioned and none forgotten, for encouraging me, believing in me, for sharing life's ups and downs with me. I cherish your friendship.

Finally, above all my beloved family:

\title{
Lasse
}

\section{Daniel and Stina, Annelie and Simon, Elliot, Tilde}

\author{
Thank you all!! \\ Jönköping, September 2016 \\ Britt-Marie Ahlander
}

The studies upon which this thesis is based were supported by grants from FUTURUM - the Academy for Healthcare, Jönköping County Council. FORRS - the Medical Research Council of Southeast Sweden, The Swedish heart lung foundation, Linköping Heart Centre and Linköping University, the County Council of Östergötland. 


\section{REFERENCES}

1. Munn, Z. and Jordan, Z., The patient experience of high technology medical imaging: a systematic review of the qualitative evidence. Radiography, 2011. 17(4): p. 323-331.

2. Adler, A.M., High technology: miracle or malady for patient care. Radiol Technol, 1990. 61(6): p. 478-81.

3. Adams, J. and Smith, T., Qualitative methods in radiography research: a proposed framework. Radiography, 2003. 9(3): p. 193-199.

4. Townsend, N., et al., Cardiovascular disease in Europe-epidemiological update 2015. Eur Heart J, 2015. 36(40): p. 2696-705.

5. Larsen, K.K., et al., Contacts to general practice and antidepressant treatment initiation after screening for anxiety and depression in patients with heart disease. Dan Med J, 2016. 63(2).

6. Luck, A., et al., Effects of video information on precolonoscopy anxiety and knowledge: a randomised trial. Lancet, 1999. 354(9195): p. 2032-5.

7. Llewelyn, S. and Ley, P., Improving patients' understanding, recall, satisfaction and compliance, in Health psychology: Process and applications, A. Broome and S. Llewelyn, Editors. 1995, Chapman \& hall: London, UK. p. 75-98.

8. Ganong William, F., Cardiovascular Disorders: Vascular Disease, in Pathophysiology of Disease. An Introduction to Clinical Medicine, F. Ganong William and J. McPhee Stephen, Editors. 2006, Appleton \&Lange: United States of America.

9. Stary, H.C., et al., A definition of initial, fatty streak, and intermediate lesions of atherosclerosis. A report from the Committee on Vascular Lesions of the Council on Arteriosclerosis, American Heart Association. Arterioscler Thromb Vasc Biol, 1994. 14(5): p. 840-56.

10. Kavey, R.-E.W., et al., American Heart Association guidelines for primary prevention of atherosclerotic cardiovascular disease beginning in childhood. Circulation, 2003. 107(11): p. 1562-1566.

11. Cresanta, J.L., et al., Prevention of atherosclerosis in childhood. Pediatr Clin North Am, 1986. 33(4): p. 835-58.

12. Dai, X., et al., Genetics of coronary artery disease and myocardial infarction. World $\mathbf{J}$ Cardiol, 2016. 8(1): p. 1-23.

13. Vinkhuyzen, A.A., et al., Estimation and partition of heritability in human populations using whole-genome analysis methods. Annu Rev Genet, 2013. 47: p. 75-95.

14. Zdravkovic, S., et al., Heritability of death from coronary heart disease: a 36-year follow-up of 20966 Swedish twins. J Intern Med, 2002. 252(3): p. 247-54.

15. De Backer, G., et al., Prevalence and management of familial hypercholesterolaemia in coronary patients: An analysis of Euroaspire IV, a study of the European Society of Cardiology. Atherosclerosis, 2015. 241(1): p. 169-75.

16. Nora, J.J., et al., Genetic epidemiologic study of early-onset ischemic heart disease. Circulation, 1980. 61(3): p. 503-8.

17. McPherson, R. and Tybjaerg-Hansen, A., Genetics of Coronary Artery Disease. Circ Res, 2016. 118(4): p. 564-78.

18. Grundy, S.M., et al., Assessment of cardiovascular risk by use of multiple-risk-factor assessment equations: a statement for healthcare professionals from the American Heart Association and the American College of Cardiology. Circulation, 1999. 100(13): p. 1481-92.

19. Khot, U.N., et al., Prevalence of conventional risk factors in patients with coronary heart disease. Jama, 2003. 290(7): p. 898-904. 
20. Pratt, L.A., et al., Depression, psychotropic medication, and risk of myocardial infarction. Prospective data from the Baltimore ECA follow-up. Circulation, 1996. 94(12): p. 3123-9.

21. Gould, K.L. and Lipscomb, K., Effects of coronary stenoses on coronary flow reserve and resistance. Am J Cardiol, 1974. 34(1): p. 48-55.

22. Gibbons, R.J., Myocardial perfusion imaging. Heart, 2000. 83(3): p. 355-60.

23. Chotenimitkhun, R. and Hundley, W.G., Pharmacological stress cardiovascular magnetic resonance. Postgrad Med, 2011. 123(3): p. 162-70.

24. Iskandrian, A.S., Verani, M.S., and Heo, J., Pharmacologic stress testing: mechanism of action, hemodynamic responses, and results in detection of coronary artery disease. $\mathrm{J}$ Nucl Cardiol, 1994. 1(1): p. 94-111.

25. Hesse, B., et al., EANM/ESC guidelines for radionuclide imaging of cardiac function. Eur J Nucl Med Mol Imaging, 2008. 35(4): p. 851-85.

26. Douglas, P.S., et al., ACCF/ASE/ACEP/AHA/ASNC/SCAI/SCCT/SCMR 2008 appropriateness criteria for stress echocardiography: a report of the American College of Cardiology Foundation Appropriateness Criteria Task Force, American Society of Echocardiography, American College of Emergency Physicians, American Heart Association, American Society of Nuclear Cardiology, Society for Cardiovascular Angiography and Interventions, Society of Cardiovascular Computed Tomography, and Society for Cardiovascular Magnetic Resonance endorsed by the Heart Rhythm Society and the Society of Critical Care Medicine. J Am Coll Cardiol, 2008. 51(11): p. 1127-47.

27. Barkhausen, J., et al., Imaging of myocardial perfusion with magnetic resonance. J. Magn. Reson. Imaging, 2004. 19(6): p. 750-757.

28. von Knobelsdorff-Brenkenhoff, F. and Schulz-Menger, J., Cardiovascular magnetic resonance imaging in ischemic heart disease. J Magn Reson Imaging, 2012. 36(1): p. 20-38.

29. Roffi, M., et al., 2015 ESC Guidelines for the management of acute coronary syndromes in patients presenting without persistent ST-segment elevation: Task Force for the Management of Acute Coronary Syndromes in Patients Presenting without Persistent ST-Segment Elevation of the European Society of Cardiology (ESC). Eur Heart J, 2016. 37(3): p. 267-315.

30. Frangogiannis, N.G., Pathophysiology of Myocardial Infarction. Compr Physiol, 2015. 5(4): p. 1841-75.

31. Bentzon, J.F., et al., Mechanisms of plaque formation and rupture. Circulation research, 2014. 114(12): p. 1852-1866.

32. Hanson, L.G., Is quantum mechanics necessary for understanding magnetic resonance? Concepts in Magnetic Resonance Part A, 2008. 32(5): p. 329-340.

33. Plewes, D.B. and Kucharczyk, W., Physics of MRI: a primer. J Magn Reson Imaging, 2012. 35(5): p. 1038-54.

34. Pooley, R.A., AAPM/RSNA physics tutorial for residents: fundamental physics of MR imaging. Radiographics, 2005. 25(4): p. 1087-99.

35. Currie, S., et al., Understanding MRI: basic MR physics for physicians. Postgrad Med J, 2013. 89(1050): p. 209-23.

36. Paschal, C.B. and Morris, H.D., K-space in the clinic. J Magn Reson Imaging, 2004. 19(2): p. 145-59.

37. McRobbie, D.W., et al., MRI From Picture to Proton. second ed. 2007, Cambridge: Cambridge University Press. 394.

38. Schenck, J.F., Safety of strong, static magnetic fields. J Cardiovasc Magn Reson, 2000. 12(1): p. 2-19.

39. Brasch, R.C., Press, W-R., and Wesbey, G.E., Characteristics of Gadolinium-DTPA Complex: A Potential NMR Contrast Agent. Classic Papers in Modern Diagnostic Radiology, 2004: p. 417.

40. McKoy, J.M., et al., Gadolinium-associated nephrogenic systemic fibrosis. Community Oncol, 2008. 5(6): p. 325-326. 
41. Thomsen, H.S., ESUR guideline: gadolinium-based contrast media and nephrogenic systemic fibrosis. Eur Radiol, 2007. 17(10): p. 2692-6.

42. McIntosh, J.F., . Möller, E, and Van Slyke, D.D., Studies of urea excretion. III: The influence of body size on urea output. J Clin Invest. , 1928. 6(3): p. 467.

43. Sterner, G., et al., Titel: Röntgenkontrastmedel och njurskador. Bättre uppfattning om riskmarkörer och uppföljning behövs. Läkartidningen, 2009: p. 1737-42.

44. Nyman, U., et al., Standardization of p-creatinine assays and use of lean body mass allow improved prediction of calculated glomerular filtration rate in adults: a new equation. Scand J Clin Lab Invest, 2006. 66(6): p. 451-68.

45. Lombardi Massimo and Carlo, B., MRI of the Heart and Vessels. 2005, Italy: SpringerVerlag Itali. 394.

46. Lanzer, P., et al., ECG-synchronized cardiac MR imaging: method and evaluation. Radiology, 1985. 155(3): p. 681-6.

47. Schwitter, J., ed. CMR Update. 2008, Juerg Schwitter: Zurich, Switzerland. 239.

48. Atkinson, D.J. and . Edelman, R.R, Cineangiography of the heart in a single breath hold with a segmented turboFLASH sequence. Radiology, 1991. 178(2): p. 357-60.

49. Barish, M.A. and Jara, H., Motion artifact control in body MR imaging. Magn Reson Imaging Clin N Am, 1999. 7(2): p. 289-301.

50. Francois, C.J., Current state of the art cardiovascular MR imaging techniques for assessment of ischemic heart disease. Radiol Clin North Am, 2015. 53(2): p. 335-44.

51. Thiele, H., et al., Functional cardiac MR imaging with steady-state free precession (SSFP) significantly improves endocardial border delineation without contrast agents. $\mathrm{J}$ Magn Reson Imaging, 2001. 14(4): p. 362-7.

52. Saloner, D., Liu, J., and Haraldsson, H., MR physics in practice: how to optimize acquisition quality and time for cardiac MR imaging. Magn Reson Imaging Clin N Am, 2015. 23(1): p. 1-6.

53. Tsao, J. and Kozerke, S., MRI temporal acceleration techniques. J Magn Reson Imaging, 2012. 36(3): p. 543-60.

54. Barkhausen, J., Hunold, P., and Waltering, K.U., MRI in coronary artery disease. Eur Radiol, 2004. 14(12): p. 2155-2162.

55. Grothues, F., et al., Comparison of interstudy reproducibility of cardiovascular magnetic resonance with two-dimensional echocardiography in normal subjects and in patients with heart failure or left ventricular hypertrophy. Am J Cardiol, 2002. 90(1): p. 29-34.

56. Greenwood, J.P., et al., Cardiovascular magnetic resonance and single-photon emission computed tomography for diagnosis of coronary heart disease (CE-MARC): a prospective trial. Lancet, 2012. 379(9814): p. 453-60.

57. Schwitter, J., et al., Superior diagnostic performance of perfusion-cardiovascular magnetic resonance versus SPECT to detect coronary artery disease: The secondary endpoints of the multicenter multivendor MR-IMPACT II (Magnetic Resonance Imaging for Myocardial Perfusion Assessment in Coronary Artery Disease Trial). J Cardiovasc Magn Reson, 2012. 14: p. 61.

58. Kim, H.W., Farzaneh-Far, A., and Kim, R.J., Cardiovascular magnetic resonance in patients with myocardial infarction: current and emerging applications. J Am Coll Cardiol, 2009. 55(1): p. 1-16.

59. Kim, R.J., Shah, D.J., and Judd, R.M., How We Perform Delayed Enhancement Imaging: How I Do. J Cardiovasc Magn Reson, 2003. 5(3): p. 505-514.

60. Rehwald, W.G., et al., Myocardial magnetic resonance imaging contrast agent concentrations after reversible and irreversible ischemic injury. Circulation, 2002. 105(2): p. 224-229.

61. Gupta, A., et al., Myocardial Infarction: Optimization of Inversion Times at Delayed Contrast-enhanced MR Imaging 1. Radiology, 2004. 233(3): p. 921-926.

62. Simonetti, O.P., et al., An improved MR imaging technique for the visualization of myocardial infarction. Radiology, 2001. 218(1): p. 215-23. 
63. Kim, R.J., et al., Relationship of MRI delayed contrast enhancement to irreversible injury, infarct age, and contractile function. Circulation, 1999. 100(19): p. 1992-2002.

64. Kim, R.J., et al., The use of contrast-enhanced magnetic resonance imaging to identify reversible myocardial dysfunction. N Engl J Med, 2000. 343(20): p. 1445-53.

65. Klinke, V., et al., Quality assessment of cardiovascular magnetic resonance in the setting of the European CMR registry: description and validation of standardized criteria. J Cardiovasc Magn Reson, 2013. 15: p. 55.

66. van der Graaf, A., et al., Cardiac magnetic resonance imaging: artefacts for clinicians. Neth Heart J, 2014. 22(12): p. 542-549.

67. Kramer, C.M., et al., Standardized cardiovascular magnetic resonance (CMR) protocols 2013 update. J Cardiovasc Magn Reson, 2013. 15: p. 91.

68. Tornqvist, E., et al., Impact of extended written information on patient anxiety and image motion artifacts during magnetic resonance imaging. Acta Radiol, 2006. 47(5): p. 474-80.

69. Di Bella, E.V., Parker, D.L. and Sinusas, A.J., On the dark rim artifact in dynamic contrast-enhanced MRI myocardial perfusion studies. Magn Reson Med, 2005. 54(5): p. 1295-9.

70. Kellman, P. and Arai, A.E., Imaging sequences for first pass perfusion-a review. $\mathrm{J}$ Cardiovasc Magn Reson, 2007. 9(3): p. 525-37.

71. Storey, P., et al., Band artifacts due to bulk motion. Magn Reson Med, 2002. 48(6): p. 1028-36.

72. Arai, A.E., Magnetic resonance first-pass myocardial perfusion imaging. Top Magn Reson Imaging, 2000. 11(6): p. 383-98.

73. Fenchel, M., et al., Multislice first-pass myocardial perfusion imaging: Comparison of saturation recovery (SR)-TrueFISP-two-dimensional (2D) and SR-TurboFLASH-2D pulse sequences. J Magn Reson Imaging, 2004. 19(5): p. 555-63.

74. Gerber, B.L., et al., Myocardial first-pass perfusion cardiovascular magnetic resonance: history, theory, and current state of the art. J Cardiovasc Magn Reson, 2008. 10: p. 18.

75. Bongartz, G., et al., European guidelines on quality criteria for computed tomography. European Commission Luxembourg, 2000.

76. Marcassa, C., et al., Clinical value, cost-effectiveness, and safety of myocardial perfusion scintigraphy: a position statement. Eur Heart J, 2008. 29(4): p. 557-563.

77. Underwood, S.R., et al., Myocardial perfusion scintigraphy: the evidence. Eur J Nucl Med Mol Imaging, 2004. 31(2): p. 261-91.

78. Paul, A.K. and Nabi, H.A., Gated myocardial perfusion SPECT: basic principles, technical aspects, and clinical applications. J Nucl Med Technol, 2004. 32(4): p. 17987; quiz 188-9.

79. McCall, D., Zimmer, L.J., and Katz, A.M., Kinetics of thallium exchange in cultured rat myocardial cells. Circ Res, 1985. 56(3): p. 370-376.

80. Melin, J.A., Becker,L.C., and Bulkley, B.H., Differences in Thallium-201 uptake in reperfused and nonreperfused myocardial infarction. Circ Res, 1983. 53(3): p. 414-419.

81. Hesse, B., et al., EANM/ESC procedural guidelines for myocardial perfusion imaging in nuclear cardiology. Eur J Nucl Med Mol Imaging, 2005. 32(7): p. 855-97.

82. Johansson, B.E. and Johansson, L., Radiofysik, in Nuklearmedicin, S.-O. Hietala, Editor. 1998, Studentlitteratur: Lund, Sweden. p. 25-54.

83. White, T. and Wollmer, P., Nuklearmedicinsk metodik., in Klinisk fysiologi, B. Jonsson, et al., Editors. 1998, Liber: Stockholm Sweden.9. 395-412.

84. Pape, M., et al., Safety and tolerability of regadenoson for myocardial perfusion imaging - first Danish experience. Scand Cardiovasc J, 2016: p. 1-19.

85. Nightingale, J.M., Murphy, F.J., and Blakeley, C., 'I thought it was just an $x$-ray': a qualitative investigation of patient experiences in cardiac SPECT-CT imaging. Nucl Med Commun, 2012. 33(3): p. 246-54.

86. Tischler, V., et al., Patient anxiety in magnetic resonance imaging centres: Is further intervention needed? Radiography, 2008. 14(3): p. 265-266. 
87. Dewey, M., Schink, T., and Dewey, C.F., Claustrophobia during magnetic resonance imaging: cohort study in over 55,000 patients. J Magn Reson Imaging, 2007. 26(5): p. 1322-1327.

88. Katz, R.C., Wilson, L., and Frazer, N., Anxiety and its determinants in patients undergoing magnetic resonance imaging. J Behav Ther Exp Psychiatry, 1994. 25(2): p. 131-134.

89. McGlynn, F.D., Karg, R., and Lawyer, S.R., Fear responses to mock magnetic resonance imaging among college students: toward a prototype experiment. J Anxiety Disord, 2003. 17(3): p. 335-47.

90. McIsaac, H.K., et al., Claustrophobia and the magnetic resonance imaging procedure. $\mathrm{J}$ Behav Med, 1998. 21(3): p. 255-268.

91. Meléndez, J.C. and McCrank, E., Anxiety-related reactions associated with magnetic resonance imaging examinations. JAMA, 1993. 270(6): p. 745-747.

92. Murphy, F., Understanding the humanistic interaction with medical imaging technology. Radiography, 2001. 7(3): p. 193-201.

93. Funk, E., Thunberg, P., and Anderzen-Carlsson, A., Patients' experiences in magnetic resonance imaging (MRI) and their experiences of breath holding techniques. J Adv Nurs, 2014. 70(8): p. 1880-90.

94. Tornqvist, E., et al., It's like being in another world--patients' lived experience of magnetic resonance imaging. J Clin Nurs, 2006. 15(8): p. 954-61.

95. Quirk, M.E., et al., Anxiety in patients undergoing MR imaging. Radiology, 1989. 170(2): p. 463-6.

96. Harris, L.M., Cumming, S.R., and Menzies, R.G., Predicting anxiety in magnetic resonance imaging scans. Int J Behav Med, 2004. 11(1): p. 1-7.

97. Hunt, C.H., et al., Wide, short bore magnetic resonance at 1.5 t: reducing the failure rate in claustrophobic patients. Clin Neuroradiol, 2011. 21(3): p. 141-4.

98. Tazegul, G., et al., Can MRI related patient anxiety be prevented? Magn Reson Imaging, 2015. 33(1): p. 180-183.

99. Kazdin, A.E., ed. Encyclopedia of psychology, volume I. . Encyclopedia of psychology, ed. A.E. Kazdin. 2000, American Psychological Association and Oxford University Press: United States of America.

100. Barlow, D.H., Unraveling the mysteries of anxiety and its disorders from the perspective of emotion theory. Am Psychol, 2000. 55(11): p. 1247.

101. Martens, E.J., et al., Scared to death? Generalized anxiety disorder and cardiovascular events in patients with stable coronary heart disease: The Heart and Soul Study. Arch Gen Psychiatry, 2010. 67(7): p. 750-758.

102. Hamang, A., et al., General anxiety, depression, and physical health in relation to symptoms of heart-focused anxiety-a cross sectional study among patients living with the risk of serious arrhythmias and sudden cardiac death. Health Qual Life Outcomes, 2011. 9(1): p. 1.

103. Spielberger, C.D., Goursch, R.L., Lushene, R.E., Manual for the State-Trait Anxiety Inventory. Palo Alto, CA: Consulting Psychologist Press, 1970.

104. Endler, N.S., et al., The multidimensionality of state and trait anxiety. Scand J Psychol, 1976. 17(1): p. 81-96.

105. Baldwin, D.S., et al., Evidence-based guidelines for the pharmacological treatment of anxiety disorders: recommendations from the British Association for Psychopharmacology. J Psychopharmaco, 2005. 19(6): p. 567-596.

106. Mann, A.H., Jenkins, R., and Belsey, E., The twelve-month outcome of patients with neurotic illness in general practice. Psychol Med, 1981. 11(3): p. 535-50.

107. Martens, R., et al., Reliability and validity of the competitive state anxiety inventory (CSAI). Psychology of motor behavior and sport, 1980: p. 91-99.

108. Zigmond, A.S. and R.P. Snaith, The hospital anxiety and depression scale. Acta Psychiatr Scand, 1983. 67(6): p. 361-70. 
109. Ollivier, L., et al., Patient experiences and preferences: development of practice guidelines in a cancer imaging department. Cancer Imaging, 2009. 9 Spec No A: p. S92-7.

110. Selim, M.A., Effect of pre-instruction on anxiety levels of patients undergoing magnetic resonance imaging examination. East Mediterr Health J, 2001. 7(3): p. 519-25.

111. Kitching, J., Patient information leaflets-the state of the art. J R Soc Med, 1990. 83(5): p. 298.

112. Ley, P. and Llewelyn, S., Improving patients' understanding, recall, satisfaction and compliance, in Health Psychology. Process and applications, A. Broome and S. Llewelyn, Editors. 1995, Chapman \& Hall: London UK.

113. Clarke, S., et al., Information for patients and staff concerning nuclear medicine. Nucl Med Commun, 1992. 13(4): p. 271-281.

114. Leckie, J., The effects of informational intervention on state anxiety and satisfaction in patients undergoing bone scan. Nucl Med Commun, 1994. 15(11): p. 921-927.

115. Carr-Hill, R.A., The measurement of patient satisfaction. J Public Health, 1992. 14(3): p. 236-249.

116. Caruso, A., et al., Breast cancer and distress resulting from magnetic resonance imaging (MRI): the impact of a psychological intervention of emotional and informative support. J Exp Clin Cancer Res, 2006. 25(4): p. 499.

117. Youssefzadeh, S., et al., Reduction of adverse events in MRI of the breast by personal patient care. Clin Radiol, 1997. 52(11): p. 862-4.

118. Doering, S., et al., Video-taped preparation of patients before hip replacement surgery reduces stress. Psychosom Med, 1998. 60(1): p. 126.

119. Lin, S.-Y., et al., The effect of an anaesthetic patient information video on perioperative anxiety: A randomised study. Eur J Anaesthesiol. (EJA), 2016. 33(2): p. 134-139.

120. Sorlie, T., et al., Video information combined with individualized information sessions: Effects upon emotional well-being following coronary artery bypass surgery--A randomized trial. Patient Educa and Couns, 2007. 65(2): p. 180-8.

121. Moran, A.E., et al., The global burden of ischemic heart disease in 1990 and 2010: the Global Burden of Disease 2010 study. Circulation, 2014. 129(14): p. 1493-501.

122. Carlsson, M., et al., Submaximal adenosine-induced coronary hyperaemia with $12 \mathrm{~h}$ caffeine abstinence: implications for clinical adenosine perfusion imaging tests. Clin Physiol Funct Imaging, 2015. 35(1): p. 49-56.

123. Hundley, W.G., et al., Society for Cardiovascular Magnetic Resonance guidelines for reporting cardiovascular magnetic resonance examinations. J of Cardiovasc Magn Reson, 2009. 11: p. 5.

124. Schwitter, J., et al., MR-IMPACT: comparison of perfusion-cardiac magnetic resonance with single-photon emission computed tomography for the detection of coronary artery disease in a multicentre, multivendor, randomized trial. Eur Heart J, 2008. 29(4): p. 480-9.

125. Klem, I., et al., Improved detection of coronary artery disease by stress perfusion cardiovascular magnetic resonance with the use of delayed enhancement infarction imaging. J Am Coll Cardio, 2006. 47(8): p. 1630-1638.

126. Kramer, C.M., When two tests are better than one: adding late gadolinium enhancement to first-pass perfusion cardiovascular magnetic resonance. J Am Coll Cardiol 2006. 47(8): p. 1639.

127. Eifert, G.H., et al., The Cardiac Anxiety Questionnaire: development and preliminary validity. Behav Res Ther, 2000. 38(10): p. 1039-1053.

128. Bjelland, I., et al., The validity of the Hospital Anxiety and Depression Scale: an updated literature review. J Psychosom Res, 2002. 52(2): p. 69-77.

129. Wolpe, J. and Lang, P.J., A Fear Survey Schedule For Use In Behaviour Therapy. Behav Res Ther, 1964. 2: p. 27-30.

130. Lukins, R., Davan, I.G.P., and Drummond, P.D., A cognitive behavioural approach to preventing anxiety during magnetic resonance imaging. J Behav Ther Exp Psychiatry, 1997. 28(2): p. 97-104. 
131. Ferreira, R. and. Murray, J, Spielberger's State-Trait Anxiety Inventory: Measuring anxiety with and without an audience during performance on a stabilometer. Percept Mot Skills 1983. 57(1): p. 15-8.

132. Ahlander, B.M., et al., Development and validation of a questionnaire evaluating patient anxiety during Magnetic Resonance Imaging: the Magnetic Resonance ImagingAnxiety Questionnaire (MRI-AQ). J Adv Nurs, 2016. 72(6): p. 1368-80.

133. Polit, D.F. and . Beck, C.T, The content validity index: are you sure you know what's being reported? Critique and recommendations. Res Nurs Health, 2006. 29(5): p. 48997.

134. Nunnally, J.C. and Bernstein, I.H., Psychometric theory 3:rd ed. 1994, New York: McGraw-Hill.

135. Fayers, P.M. and Machin, D., Quality of Life. The assessment, analysis and interpretation of patient-reported outcomes. Second ed. 2009, Eastbourne, United Kingdom: Wiley. 544.

136. Streiner, D.L. and Norman, G.R., Health Measurments Scales a practical guide to their development and use. Fourth ed. 2008, New York, USA: Oxford University Press. 431.

137. Hoyle, R.H. and Duvall, J.L., Determining the number of factors in exploratory and confirmatory factor analysis in The SAGE Handbook of Quantitative Methodology for the Social Sciences K. David, Editor. 2004, SAGE Publications: USA. p. 301-314.

138. Dahlberg, G., Statistical methods for medical and biological students. Statistical Methods for Medical and Biological Students., 1940.

139. Landis, J.R. and . Koch, G.G, The measurement of observer agreement for categorical data. Biometrics, 1977. 33(1): p. 159-174.

140. World Medical Association, World Medical Association Declaration of Helsinki. Ethical principles for medical research involving human subjects. Bulletin of the World Health Organization, 2001. 79(4): p. 373.

141. ICH Harmonised Tripartite Guideline, Guideline for good clinical practice. Postgrad Med J, 2001. 47(1): p. 45-50.

142. Beauchamp, T.L. and Childress, J.F., Principles of biomedical ethics. 2013, New York : Oxford University Press. xvi, $459 \mathrm{p}$.

143. Sveriges Riksda., Personuppgiftslag (1998:204). 1998, Sveriges Riksdag: http://www.riksdagen.se/sv/DokumentLagar/Lagar/Svenskforfattningssamling/Personuppgiftslag-1998204_sfs-1998-204/.

144. The Belmont Report. Ethical principles and guidelines for the protection of human subjects of research. J Am Coll Dent, 2014. 81(3): p. 4-13

145. Gustafsson, B., H. Göran., and B. Petterson, God Forskningssed. 2011, Vetenskapsrådet: Stockholm.

146. Wolff, S.D., et al., Myocardial first-pass perfusion magnetic resonance imaging - A multicenter dose-ranging study. Circulation, 2004. 110(6): p. 732-737.

147. Pett, M.A., Lackey, N.R., and Sullivan, J.J., Making Sense of Factor Analysis: the use of factor analysis for instrument development in health care research. 2003, United States of America: Sage Publications Inc.

148. MacCallum, R.C., et al., Sample size in factor analysis. Psychological methods, 1999. 4(1): p. 84.

149. Garcia, M.J., ACCF/AHA Clinical Competence Statement on Cardiac Imaging With Computed Tomography and Magnetic Resonance. J Am Coll Cardiol, 2005. 46(2).

150. Ferreira, P.F., et al., Cardiovascular magnetic resonance artefacts. J Cardiovasc Magn Reson, 2013. 15(1): p. 41.

151. Bonanad, C., et al., Prediction of long-term major events soon after a first ST-segment elevation myocardial infarction by cardiovascular magnetic resonance. Eur J Radiol, 2016. 85(3): p. 585-92.

152. Huber, A., et al., Single-shot inversion recovery TrueFISP for assessment of myocardial infarction. AJR Am J Roentgenol, 2006. 186(3): p. 627-633.

153. Socialstyrelsen, Nationella riktlinjer för hjärtsjukvård, vetenskapligt underlag. 2015, Socialstyrelsen: http://www.socialstyrelsen.se/publikationer2015/2015-10-4. p. 120. 
154. Fujimoto, S., et al., Study of the predictors and lesion characteristics of ischemic heart disease patients with false negative results in stress myocardial perfusion single-photon emission tomography. Circ J., 2006. 70(3): p. 297-303.

155. Bratis, K. and Nagel, E., Variability in quantitative cardiac magnetic resonance perfusion analysis. J Thorac Dis, 2013. 5(3): p. 357-9.

156. Grey, S.J., Price, G., and Mathews, A., Reduction of anxiety during MR imaging: a controlled trial. Magn Reson Imaging, 2000. 18(3): p. 351-355.

157. Terwee, C.B., et al., Quality criteria were proposed for measurement properties of health status questionnaires. J Clin Epidemiol, 2007. 60(1): p. 34-42.

158. Carlsson, S. and Carlsson, E., 'The situation and the uncertainty about the coming result scared me but interaction with the radiographers helped me through': a qualitative study on patients' experiences of magnetic resonance imaging examinations. J Clin Nurs, 2013. 22(21-22): p. 3225-34.

159. Wilson-Barnett, J., Stress in hospital: patients' psychological reactions to illness and health care. 1979: Churchill Livingstone.

160. Easton, K., et al., Prevalence and Measurement of Anxiety in Samples of Patients With Heart Failure: Meta-analysis. J Cardiovasc Nurs, 2016. 31(4): p. 367-79. 


\section{APPENDIX I}

\section{Magnetic Resonance Imaging- Anxiety Questionnaire (MRI-AQ)}

INSTRUCTIONS: Below are some statements that can be used to describe your feelings. Read each statement and circle the number 1 to 4 that best describes your feelings during the MRI examination. Do not reflect too much on any statement, but respond in the way you think best corresponds to your feelings during the examination.

\begin{tabular}{|c|c|c|c|c|c|}
\hline & & Not at all & Somewhat & Moderately & Very much \\
\hline $1 *$ & I felt that I controlled the situation & 1 & 2 & 3 & 4 \\
\hline 2 & I had palpitation & 1 & 2 & 3 & 4 \\
\hline 3 & I found it hard to breath & 1 & 2 & 3 & 4 \\
\hline 4 & I was afraid & 1 & 2 & 3 & 4 \\
\hline 5 & I wanted to come out & 1 & 2 & 3 & 4 \\
\hline 6 & I panicked & 1 & 2 & 3 & 4 \\
\hline $7 *$ & I felt relaxed & 1 & 2 & 3 & 4 \\
\hline $8^{*}$ & I felt safe & 1 & 2 & 3 & 4 \\
\hline 9 & I worried in advance & 1 & 2 & 3 & 4 \\
\hline $10 *$ & I felt calm & 1 & 2 & 3 & 4 \\
\hline 11 & $\begin{array}{l}\text { I had to force myself to manage the } \\
\text { situation }\end{array}$ & 1 & 2 & 3 & 4 \\
\hline 12 & $\begin{array}{l}\text { Self-control was required when going } \\
\text { through the examination }\end{array}$ & 1 & 2 & 3 & 4 \\
\hline 13 & I needed support and encouragement & 1 & 2 & 3 & 4 \\
\hline 14 & I wished to have someone with me & 1 & 2 & 3 & 4 \\
\hline 15 & I needed more detailed information & 1 & 2 & 3 & 4 \\
\hline
\end{tabular}

Items marked $*$ are to be inverted before calculation. Higher score will then indicate higher level of anxiety. 


\section{APPENDIX II}

\section{Magnetic Resonance Imaging- Anxiety Questionnaire (MRI-AQ)}

INSTRUKTION: Nedan följer några påståenden som man kan använda för att beskriva hur man känner sig. Läs varje påstående och ringa in den av siffrorna 1 till 4 som bäst svarar mot hur du kände dig under magnetkameraundersökningen. Fundera inte för mycket på något påstående utan svara såsom Du tycker bäst passade in hur du kände Dig vid undersökningen

\begin{tabular}{|c|c|c|c|c|c|}
\hline & & Inte alls & $\begin{array}{c}\text { Ganska } \\
\text { lite }\end{array}$ & $\begin{array}{l}\text { Ganska } \\
\text { mycket }\end{array}$ & Mycket \\
\hline $1 *$ & $\begin{array}{l}\text { Jag kände att jag behärskade } \\
\text { situationen. }\end{array}$ & 1 & 2 & 3 & 4 \\
\hline 2 & Jag fick hjärtklappning & 1 & 2 & 3 & 4 \\
\hline 3 & Jag hade svårt att andas & 1 & 2 & 3 & 4 \\
\hline 4 & Jag kände rädsla & 1 & 2 & 3 & 4 \\
\hline 5 & Jag ville komma ut & 1 & 2 & 3 & 4 \\
\hline 6 & Jag fick panik & 1 & 2 & 3 & 4 \\
\hline $7 *$ & Jag kände mig avslappnad & 1 & 2 & 3 & 4 \\
\hline $8^{*}$ & Jag kände mig säker & 1 & 2 & 3 & 4 \\
\hline 9 & Jag oroade mig i förväg & 1 & 2 & 3 & 4 \\
\hline $10^{*}$ & Jag kände mig lugn & 1 & 2 & 3 & 4 \\
\hline 11 & $\begin{array}{l}\text { Jag fick anstränga/bemöda mig för } \\
\text { att klara av situationen }\end{array}$ & 1 & 2 & 3 & 4 \\
\hline 12 & $\begin{array}{l}\text { Det krävdes självkontroll för att } \\
\text { kunna genomföra undersökningen }\end{array}$ & 1 & 2 & 3 & 4 \\
\hline 13 & Jag behövde stöd och uppmuntran & 1 & 2 & 3 & 4 \\
\hline 14 & Jag hade velat ha någon med mig & 1 & 2 & 3 & 4 \\
\hline 15 & $\begin{array}{l}\text { Jag hade behov av mer detaljerad } \\
\text { information }\end{array}$ & 1 & 2 & 3 & 4 \\
\hline
\end{tabular}

Frågor markerade * inverteras före kalkylering. Då kommer höga värden alltid att indikera högre ångest. 